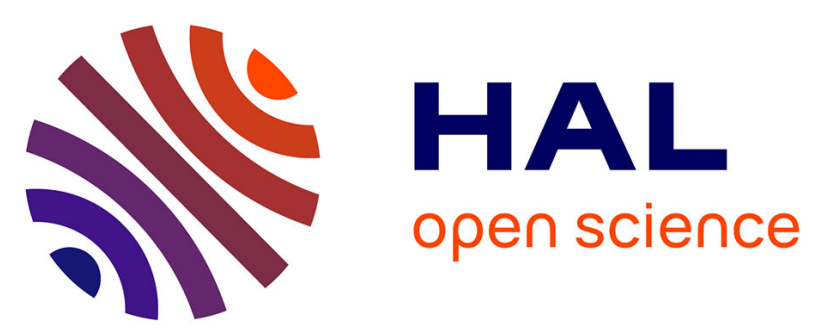

\title{
Altimetric sampling and mapping procedures induce spatial and temporal aliasing of the signal - characteristics of these aliasing effects in the Mediterranean Sea

\author{
M.-I. Pujol, G. Larnicol, G. Dibarboure, F. Briol
}

\section{To cite this version:}

M.-I. Pujol, G. Larnicol, G. Dibarboure, F. Briol. Altimetric sampling and mapping procedures induce spatial and temporal aliasing of the signal - characteristics of these aliasing effects in the Mediterranean Sea. Ocean Science Discussions, 2007, 4 (4), pp.571-622. hal-00331132

\section{HAL Id: hal-00331132 \\ https://hal.science/hal-00331132}

Submitted on 17 Jul 2007

HAL is a multi-disciplinary open access archive for the deposit and dissemination of scientific research documents, whether they are published or not. The documents may come from teaching and research institutions in France or abroad, or from public or private research centers.
L'archive ouverte pluridisciplinaire HAL, est destinée au dépôt et à la diffusion de documents scientifiques de niveau recherche, publiés ou non, émanant des établissements d'enseignement et de recherche français ou étrangers, des laboratoires publics ou privés. 
Altimetric data in the Mediterranean Sea

M.-I. Pujol et al.

\section{Altimetric sampling and mapping procedures induce spatial and temporal aliasing of the signal - characteristics of these aliasing effects in the Mediterranean Sea}

M.-I. Pujol ${ }^{1}$, G. Larnicol ${ }^{2}$, G. Dibarboure ${ }^{2}$, and F. Briol ${ }^{2}$

${ }^{1}$ INGV, Via Donato Creti 12, 40128 Bologna, Italy

${ }^{2}$ CLS Space Oceanography Division, 8-10 Rue Hermès, 31526 Ramonville St. Agne, France

Received: 15 May 2007 - Accepted: 18 June 2007 - Published: 17 July 2007

Correspondence to: M.-I. Pujol (pujol@bo.ingv.it)

Title Page

Abstract

Introduction

Conclusions

References

Tables

Figures

14

$>1$

4

Back

Full Screen / Esc

Printer-friendly Version

Interactive Discussion 


\section{Abstract}

This study deals with spatial and temporal aliasing of the sea surface signal and its restitution with altimetric maps of Sea Level Anomalies (SLA) in the Mediterranean Sea. Spatial and temporal altimetry sampling, combined with a mapping process, are 5 unable to restore high-frequency (HF) surface variability. In the Mediterranean Sea, it has been shown that signals whose intervals are less than 30-40 days are largely underestimated, and the residual HF restitution signal contains characteristic errors which make it possible to identify the spatial and temporal sampling of each satellite.

The origin of these errors is relatively complex. Three main effects are involved: the 10 sampling of the HF long-wavelength (LW) signal, the correction of this signal's aliasing and the mapping procedure.

- The sampling depends on the characteristics of the satellites considered, but generally induces inter-track bias that needs to be corrected before the mapping procedure is applied.

- Correcting the aliasing of the HF LW signal, carried out using a barotropic model output and/or an empirical method, is not perfect. In fact, the baroclinic part of the HF LW signal is neglected and the numerical model's capabilities are limited by the spatial resolution of the model and the forcing. The empirical method cannot precisely control the corrected signal.

- The mapping process, which is optimised to improve restitution of mesoscale activity, does not propagate the LW signal far from the satellite tracks.

Even though these residual errors are very low with respect to the total signal, their signature may be visible on maps of SLAs. However, these errors can be corrected by more careful consideration of their characteristics in terms of spatial distribution induced by altimetric along-track sampling. They can also be attenuated by increasing the altimetric spatial coverage through the merging of different satellites.
OSD

4, 571-622, 2007

Altimetric data in the Mediterranean Sea

M.-I. Pujol et al.

Title Page

Abstract Introduction

Conclusions

References

Tables

Figures

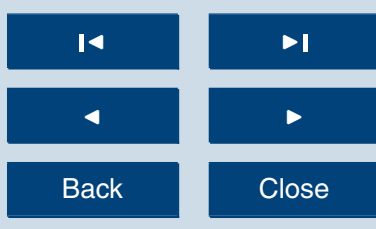

Full Screen / Esc

Printer-friendly Version

Interactive Discussion 
Ultimately, the HF signal, which is missing in maps of SLA, can be completed using a numerical model in order to estimate the total surface signal. The barotropic HF $(<30$ days) component accounts for nearly $10 \%$ of the total variability. Locally, it contributes nearly $25 \%$ of the total variance.

\section{Introduction}

Since the 1990s, numerous efforts have been made to improve altimetric processing and obtain accuracy of almost $2 \mathrm{~cm}$, thus improving the precision of SLA maps. These efforts consisted in the correction of along-track measurements (Le Traon and Ogor, 1998; Carrère et al., 2005; etc.) as well as improvements to the mapping procedure 10 and its ability to merge information from different satellites (Ducet et al., 2000; Ayoub et al., 1998; Le Traon et al., 1995, 1998; etc.). In this way, global ocean products were largely improved. However, studies of limited areas have led us to continue the work already begun in order to improve restitution of SLA in these limited areas. In the case of the Mediterranean Sea, most of the improvements to altimetric processing have been achieved in the context of the MERSEA/MFSTEP projects. Studies using altimetry data dedicated to the Mediterranean Sea have demonstrated the need to apply specific processing in this basin. In this paper, we focus on the difficulties involved in correcting the HF LW signal.

For the last few years, thanks to improvements in numerical models, it has been 20 possible to estimate the HF LW surface variability with relatively high accuracy. Model capabilities have been exploited to describe this signal and estimate its contribution to the total surface variability. The importance of this signal at high latitudes was underlined by Fukumori et al. (1998) as the authors showed that at these latitudes, more than $50 \%$ of the signal variability in periods of less than 180 days can be accounted

by the signal for periods of less than 20 days. However, the Mediterranean Sea was not included in the study area considered by the authors. So the HF LW surface variability in this basin has still not been well documented. Moreover, the HF variability
OSD

4, 571-622, 2007

Altimetric data in the Mediterranean Sea

M.-I. Pujol et al.

Title Page

Abstract Introduction

Conclusions References

Tables Figures

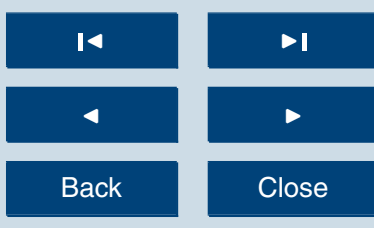

Full Screen / Esc

Printer-friendly Version

Interactive Discussion 
in the Mediterranean Sea also includes its specific response to inverse barometer (IB) variability. Le Traon and Gauzelin (1997) showed that the semi-enclosed character of the sea induces a delayed response to the IB in the basin.

Whereas the ability of altimetry data to observe a large part of the surface variabil-

5 ity has essentially been demonstrated, the HF component still represents a significant limit to the measurements. In fact, as the revisit frequency of the measurement is several days (10 days for TP and 35 days for ERS), the higher frequency signal is aliased. Moreover, the exploitation of altimetry data from gridded maps, which is often the case, implies that the HF LW variability is removed from the data before the mapping pro10 cedure is applied in order to ensure the spatial coherence of the maps generated (Le Traon et al., 1998). Correcting the HF signal from the altimetry data is also an important issue for altimetry data assimilation in numerical models. A first methodology for correcting HF atmospheric effects was developed by Le Traon et al. (1998) and consisted in an empirical correction. More recently, another methodology, using 15 a barotropic model output, which is a better way of taking into account the physical process responsible for HF surface variability, was developed by Carrère et al. (2007) ${ }^{1}$. However, specific studies in the Mediterranean Sea have shown that these corrections, as currently used, do not entirely correct for the aliasing effect, leading to characteristic residual error signals on SLA maps.

20 This paper is organised as follows: in Sect. 2, the MOG2D and altimetry data set used are described. In Sect. 3, the main characteristics of the HF $\left(>30^{-1}\right.$ days $^{-1}$ ) LW barotropic signal given by the MOG2D model are described, and specific errors of the HF LW signal's spatial and temporal aliasing are highlighted using an Observing System Simulation Experiment (OSSE). Section 4 focuses on the real altimetry data. 25 The importance of the error signal was quantified from 11 years (1993-2003) of SLA maps and solutions for correcting them have been included. In Sect. 5, the capabilities

${ }^{1}$ Carrère, L., Volkov, D.,Le Traon, P.-Y., Schaeffer, P., Boone, C., Faugère, Y., and Gaspar, P.: Reducing the aliasing of the high frequency signals in altimeter data: empirical and modelbased approaches, J. Atmos. Oceanic Technol., in review, 2007.

OSD

4, 571-622, 2007

\section{Altimetric data in the Mediterranean Sea}

M.-I. Pujol et al.

\section{Title Page}

Abstract Introduction

Conclusions References

Tables Figures

1

14

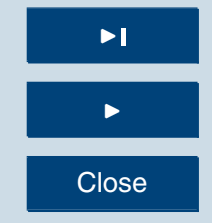

Back

Full Screen / Esc

Printer-friendly Version

Interactive Discussion

EGU 
of the MOG2D numerical model are exploited to complete the altimetry data set and obtain an estimate of the total surface variability of the signal. Section 6 resumes and concludes this study.

\section{Data processing}

\section{$5 \quad 2.1$ MOG2D model}

In this study, the MOG2D model was used to obtain the high-frequency longwavelength barotropic signal. MOG2D is a barotropic, non-linear, time step model which uses finite element spatial discretisation. The details of the model are given in Carrère and Lyard (2003).

10 The accuracy of this model in reproducing the HF barotropic variability was demonstrated by Carrère (2003). However, its ability to reproduce the LF barotropic variability was limited by the considerable energy dissipation which was parameterised (Carrère, 2003).

The model was used in its global version without considering the gravity wave effect. 15 It was forced with pressure and wind speed from the six-hour ECMWF analysis field (ECMWF, 1991). The inverse barometer effect was removed from the output in order to consider only the dynamic part of the signal. The six-hour outputs of the model in the Mediterranean Sea over the 11-year period (1993-2003) were used. They were interpolated on $1 / 4^{\circ}$ regularly-gridded maps.

\subsection{Altimetry data}

This study used altimetry data from the Topex/Poseidon (TP), Jason-1 (J1), Envisat (EN) and ERS-1/ERS-2 satellite altimeters over the 11-year period (1993-2003). The along-track data were combined and interpolated to build a homogeneous time set of weekly and regularly gridded $\left(1 / 8^{\circ} \times 1 / 8^{\circ}\right.$ spatial resolution) altimetric maps. The

\section{Altimetric data in the Mediterranean Sea}

M.-I. Pujol et al.

\section{Title Page}

Abstract Introduction

Conclusions References

Tables

Figures

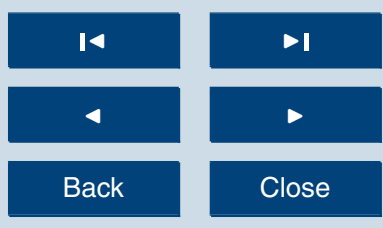

Full Screen / Esc

Printer-friendly Version

Interactive Discussion 
methodology used was the same as the one described by Larnicol et al. (2002), or Pujol and Larnicol (2005).

Complementary satellites were merged only twice: TP+ERS at the beginning of the period and $\mathrm{J} 1+\mathrm{EN}$ at the end.

5 Firstly, a homogeneous and inter-calibrated data set was obtained by performing a global crossover adjustment, using T/P as the reference mission (Le Traon and Ogor, 1998). Then geophysical corrections (IB, tides, tropospheric, ionospheric) were applied. Along-track data were resampled every $7 \mathrm{~km}$ using cubic splines and the SLA were computed by extracting a seven-year mean SSH corresponding to the (199310 1999) period. Measurement noise was reduced by applying Lanczos (cut-off wavelength of $42 \mathrm{~km}$ ) and median $(21 \mathrm{~km})$ filters. An additional validation scheme was applied to remove the remaining invalid points. This consisted in removing any data exhibiting differences which were too great when compared with the previous analysis (3 $\sigma$ criteria).

15 Data were then interpolated over a regular $1 / 8^{\circ} \times 1 / 8^{\circ}$ grid, every seven days, using an Objective Analysis (OA) method combining the different altimeter missions (Ducet et al., 2000) with a constant space and time isotropic correlation radius of $100 \mathrm{~km}$ and 10 days (Pujol and Larnicol, 2005). The presence of islands and complex coastlines was taken into account to avoid using observations that did not come from the same basin (i.e. Adriatic and Tyrrhenian Seas). Furthermore, measurement noise (variance of $3 \mathrm{~cm}^{2}$ for T/P and $\mathrm{J} 1$, and $4.5 \mathrm{~cm}^{2}$ for ERS1/2 and EN) was corrected during the mapping procedure.

The LW signal was also taken into account. The performance of the different corrections has been analysed in this paper. In this way, three different altimetry data sets were generated. Two of them were generated using an empirical method described by Le Traon et al. (1998). Its effect was to reduce inter-track bias mainly induced by the HF LW signal along-track sampling but also by errors in estimating the satellite's orbit or correcting the inverse barometer effect that was not part of the dynamic signal studied. This correction involves considering the bias as an along-track correlated

OSD

4, 571-622, 2007

\section{Altimetric data in the Mediterranean Sea}

M.-I. Pujol et al.

\section{Title Page}

Abstract Introduction

Conclusions References

Tables Figures

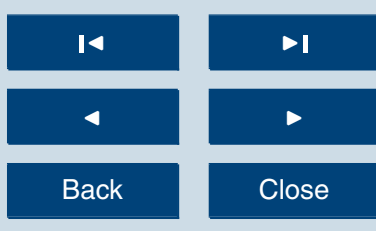

Full Screen / Esc

Printer-friendly Version

Interactive Discussion 
measurement error. This error enters into the estimate of the error covariance matrices needed in the OA mapping procedure. In practice, estimating this error covariance requires 1) an estimate of the variance associated with the inter-track bias and 2) a spatial/temporal domain in which data involved in covariance computation can be se-

5 lected. Two different parameterisations were analysed. The first one considered the error signal variance associated with the LW signal as $9 \mathrm{~cm}^{2}$ for T/P and J1, and $15 \mathrm{~cm}^{2}$ for ERS1/2 and EN. For each measurement location, the correction was computed with respect to a spatial/temporal domain of $250 \mathrm{~km}$ and 10 days. The data set obtained with this correction was noted as AOS_250.

10 For the second experiment, the spatial/temporal domain was enlarged to $600 \mathrm{~km}$ and 10 days while the signal variance remained unchanged. This data set was noted as AOS_600.

The third data set was generated by applying a model-based LW correction as described by Carrère et al. (2007) ${ }^{1}$. The output of the MOG2D barotropic global ocean 15

model, forced by the ECMWF surface pressure and wind speed, was considered to be a good estimate of the HF LW surface variability to be corrected and was directly removed from the altimetry measurements. This model-based correction was completed with the previous empirical correction in order also to correct the signals which were not simulated with MOG2D, such as orbital errors or residual tidal correction. In this case, the variance associated with the signal was fixed at $9 \mathrm{~cm}^{2}$ for T/P and $\mathrm{J} 1$, and $15 \mathrm{~cm}^{2}$ for ERS1/2 and EN. The correction was estimated considering a spatial/temporal range of $250 \mathrm{~km}$ and 10 days. The data set thus obtained was noted as AOS_MOG2D.

\subsection{Tide gauge data}

Tide gauge data were compared with altimetry and model products. The mean part 25 Protezione dell'Ambiente et per I servizi Tecnici). Some of them come from the WOCE network (GLOSS/CLIVAR near real-time data).

In order to compare the different data sets, the tide gauge signal was processed in

OSD

$4,571-622,2007$

\section{Altimetric data in the Mediterranean Sea}

M.-I. Pujol et al.

\section{Title Page}

Abstract Introduction

Conclusions References

Tables Figures

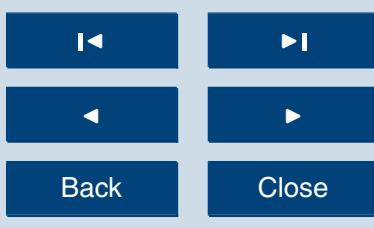

Full Screen / Esc

Printer-friendly Version

Interactive Discussion 
order to be consistent with altimetry/MOG2D model data. Therefore, some specific corrections were applied. First ocean-tide signals were removed by applying different low-pass filters (Lefèvre and Sénant, 2005). Then the static inverse barometer effect was removed from the data. Finally, original one-hour data were daily-averaged. Only 5 daily means computed with a significant amount of data were considered. The limit was arbitrarily fixed at $50 \%$ of the maximum amount of data possible. As some inconsistencies in the time series available were observed (a bias may be detected after a manoeuvre involving the tide gauge station for instance), we considered each tide gauge station over different periods. The position and the different periods considered 10 for each tide gauge station used are shown in Table 1.

\section{Characterisation of the high-frequency aliasing effect in the Altimeter Observ- ing System}

Mapped SLA products are often used to describe sea surface variability. However, these products do not allow us to restore the HF signal accurately. In fact, part of 15 the signal is smoothed by the interpolation. Moreover, these SLA maps are usually generated by merging the information from different altimeters, that sample the signal with different spatial coverage and revisit frequencies. Ultimately, both temporal and spatial aliasing of the HF signal are induced by the altimetric sampling and mapping procedure. The aim of this section is to characterise these aliasing effects.

\subsection{Methodology}

The aliasing effect induced by the Altimeter Observing System (AOS) was studied using an OSSE.

Barotropic surface variability simulated with the MOG2D model (Sect. 2.1) was intended to represent the "true" surface signal.

First, a synthetic altimetric observation data set was obtained by interpolating this
OSD

4, 571-622, 2007

Altimetric data in the Mediterranean Sea

M.-I. Pujol et al.

Title Page

Abstract Introduction

Conclusions References

Tables Figures

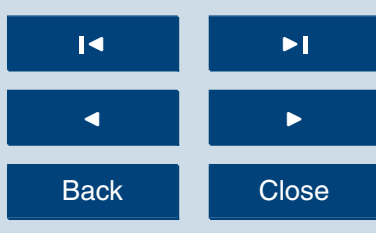

Full Screen / Esc

Printer-friendly Version

Interactive Discussion 
"true" field on the altimetric measurement location. In this way, a spatial and linear interpolation was used.

Then, the along-track synthetic observations were used to restore the ocean surface state. Weekly gridded maps with $1 / 4^{\circ}$ spatial resolution were generated. The 5 methodology was the same as that described in Sect. 2.2 except that only LW errors were considered. In particular, inter-satellite bias, measurement noise or orbit error, absent from the MOG2D output, were not reintroduced in the synthetic observation field. Synthetic altimetric observations were resampled every $7 \mathrm{~km}$, then the $O A$ was directly applied to generate weekly maps combining the different synthetic altimeter 10 data sets, with a constant correlation range of $100 \mathrm{~km}$ and 10 days. Inter-track LW errors, induced by the sampling of the HF LW surface signal, were corrected using the empirical method described by le Traon et al. (1998) (Sect. 2.2). Two parameterisations were tested. The first one considered a spatial/temporal domain of $250 \mathrm{~km}$ and 10 days, and an error signal variance of $9 \mathrm{~cm}^{2}$ and $15 \mathrm{~cm}^{2}$ for TP/J1 and ERS/EN 15 respectively. In the following sections, the signal obtained with this parameterisation will be noted as OSSE_250. The other parameterisation tested involved considering a spatial/temporal domain of $600 \mathrm{~km}$ and 10 days, while the variance of the error signal remained unchanged. This signal was noted as OSSE_600.

Finally, the reconstructed surface state thus obtained was compared to the "true" 20 reference signal in order to identify the error signal induced by the HF aliasing in AOS. This exercise was carried out over the 11-year period (1993-2003).

3.2 Principal characteristics of the barotropic dynamic signal in the Mediterranean Sea - description of the reference simulation

In this section, we describe the dynamic barotropic signal simulated by MOG2D and 25 considered as the "true" reference signal. Here our intention is not to characterise this signal fully, but rather to highlight its essential information, in order to introduce the study described in the subsequent sections.

As this paper deals with the difficulties involved in in observing/restoring HF surface 579

\section{OSD}

4, 571-622, 2007

Altimetric data in the Mediterranean Sea

M.-I. Pujol et al.

\section{Title Page}

Abstract Introduction

Conclusions References

Tables Figures

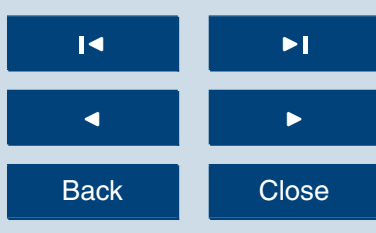

Full Screen / Esc

Printer-friendly Version

Interactive Discussion 
variability with the AOS, we have mainly focused on the HF component of the signal. Here we considered the HF component as a signal whose frequency was higher than $30^{-1}$ days $^{-1}$. This choice was determined by the difficulties in using altimetry data to restore this signal, as described in Sect. 3.4.

5 The mean variability (in term of variance) of the HF LW barotropic signal over the [1993-2003] period is given in Fig. 1. The mean variance is nearly $7.6 \mathrm{~cm}^{2}$ over the whole sea. However, the mean variance is higher in the eastern part of the basin with $9 \mathrm{~cm}^{2}$ compared with $7 \mathrm{~cm}^{2}$ measured in the western part. Some specific areas of high $\mathrm{HF}$ barotropic variability $\left(>15 \mathrm{~cm}^{2}\right)$ have also been identified. This is the case in the 10 northern Adriatic, the Gulf of Gabès and the southern coast of the Ionian Sea or along the Liguro-Provençal coast especially in the Gulf of Lions. In these regions, the higher $\mathrm{HF}$ barotropic response is due to both the low bathymetry favourable to barotropic signals and the higher variable atmospheric forcing (surface pressure and winds) in these areas.

15 Finally the Empirical Orthogonal Function (EOF) decomposition for the HF LW barotropic signal showed that the signal responsible for the variance observed can be summarised in two main modes shown in Fig. 2. The first mode, largely predominant, accounts for nearly $85.5 \%$ of the signal variance. It represents the mean variability of the basin, higher in the eastern part. The temporal component is clearly governed by 20 a seasonal signal with higher variability in autumn/winter. The second mode, which accounts for nearly $8 \%$ of the variance, suggests a western/eastern dipole variability induced by modulation in the Strait of Sicily. However, the variability observed in the Ionian Sea appears weaker than in the Levantine basin, except along the current in the southern lonian. This mode's temporal variability is also largely governed by a seasonal modulation of the signal, again with higher variability in autumn/winter.

While the low frequency (LF) barotropic component simulated by MOG2D is not realistic, since it is greatly attenuated by the energy-dissipation scheme (Carrère, 2003), its contribution to the variability of the total reference signal is not insignificant. In fact its contribution has the effect of increasing the signal's mean variability by nearly

OSD

4, 571-622, 2007

\section{Altimetric data in the Mediterranean Sea}

M.-I. Pujol et al.

\section{Title Page}

Abstract Introduction

Conclusions References

Tables Figures

I

14

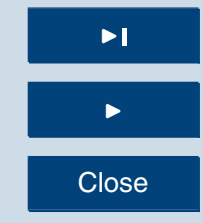

Full Screen / Esc

Printer-friendly Version

Interactive Discussion

EGU 
$4.5 \mathrm{~cm}^{2}$ bringing the signal's total mean variability to $12 \mathrm{~cm}^{2}$. However, this contribution is nearly uniform over the whole sea and thus poorly modifies the main characteristics of the signal variability with respect to the HF component alone.

In this way, the EOF decomposition of the total simulated barotropic signal identified 5 the same two main modes as previously described for the HF component alone. The first main mode was responsible for $86.4 \%$ of the signal variance and the second mode accounted for $7.7 \%$ of the variance (not shown).

The results obtained with MOG2D indicate that wind speed and surface pressure are the main forcing factors responsible for barotropic HF LW surface variability (Carrère,

10 2003). However, the complexity of the phenomena involved makes it difficult to determine the direct relationship between the two signals. In fact, the response of the basin is also constrained by the presence of different straits. Fukumori et al. (2007) especially underlined the connection between intra-annual surface variability in the Mediterranean Sea and water mass exchange through the Strait of Gibraltar, showing that such basinwide surface variability is induced by wind variability west of the Strait of Gibraltar. Moreover, Le Traon and Gauzelin (1997) also showed that the relationship between atmospheric surface pressure and Mediterranean surface barotropic variability is modulated by the Strait of Gibraltar. In fact the authors identified the delayed response of the basin to the inverse-barometer effect.

20 In the following sections we analyse the altimetric signal obtained using the OSSE in order to explore how well the AOS rstores the surface signal, better characterising the aliasing effect of the measurement.

\subsection{Ability of altimetry to restore the total signal}

For this study, we considered the OSSE_250 (Sect. 3.1) signal over the period [19932003]. In fact, the parameterisation used to generate this signal corresponds to the one currently used for the Mediterranean Sea.

The total mean variance of this signal is nearly $3 \mathrm{~cm}^{2}$ (Fig. 3). This value, largely

OSD

4, 571-622, 2007

Altimetric data in the Mediterranean Sea

M.-I. Pujol et al.

\section{Title Page}

Abstract Introduction

Conclusions References

Tables Figures

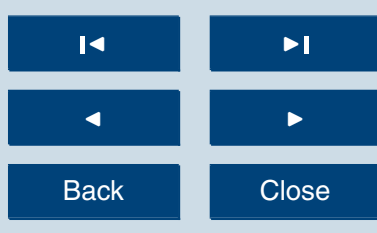

Full Screen / Esc

Printer-friendly Version

Interactive Discussion 
weaker than the reference signal (Sect. 3.2), can be directly associated with the absence of the signal for intervals of less than 14 days (weekly maps, Sect. 3.1), whereas it represents a significant part of the variability in the reference MOG2D signal. However the spatial distribution of the signal variability is well restored with the OSSE. The 5 difference between the eastern and western basin is observed with nearly $2 \mathrm{~cm}^{2}$ of variance in the western basin and nearly $3.5 \mathrm{~cm}^{2}$ in the eastern basin. Moreover, as highlighted with the reference MOG2D data set (Sect. 3.2), larger values are observed in specific areas like the Gulf of Lions $\left(5 \mathrm{~cm}^{2}\right)$, the northern Adriatic $\left(7 \mathrm{~cm}^{2}\right)$ the southern coast of the Ionian Sea $\left(6 \mathrm{~cm}^{2}\right)$, the Aegean Sea $\left(6 \mathrm{~cm}^{2}\right)$ and along the Levantine 10 coasts $\left(5 \mathrm{~cm}^{2}\right)$.

The EOF decomposition of this total OSSE_250 signal (Fig. 4) also revealed the main characteristics of the original signal. In fact, the first mode obtained clearly shows that the basin-wide variability is slightly greater in the eastern basin. This mode accounts for nearly $54 \%$ of the variance. As previously highlighted with the reference signal, this 15 fourth mode, that accounts for nearly $3.6 \%$ of the variance. The annual modulation of
the temporal components associated with these two modes (not shown) varies more in autumn/winter.

So ultimately, overall, the AOS correctly restores the signal's main characteristics. 20 However, its ability remains limited.

First for the frequencies actually restored: as mentioned earlier, the AOS is limited by the spatial revisit capability of the measurement that also limits the frequency of the maps generated. The weekly nature of the maps generated, limiting the reconstruction of the signal for intervals of higher than 14 days only, thus contributes to the weaker 25 variance explained by both modes in the OSSE_250 signal with respect to the MOG2D reference signal.

However, part of the real signal is aliased by the observing system, which also contributes to the alteration of the restored signal. In this way, as the reader has noted, the two characteristic modes deduced for the OSSE_250 signal (Fig. 4) are altered by
OSD

4, 571-622, 2007

\section{Altimetric data in the Mediterranean Sea}

M.-I. Pujol et al.

\section{Title Page}

Abstract Introduction

Conclusions References

Tables Figures

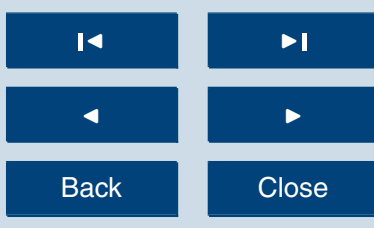

Full Screen / Esc

Printer-friendly Version

Interactive Discussion 
a shorter wavelength signal. This noise signal is characteristic of the aliasing effect induced by the altimetric sampling/mapping of the HF LW surface signal. It is discussed in Sect. 3.4.2.

Reducing this aliasing effect is a major challenge. First because it directly contributes 5 to the better quality of the AOS products. In this way, the improved correction of the aliasing effect also has a significant impact on many applications involving altimetry data. This is the case for instance with assimilation systems that need the utmost control of the altimetric signal.

However, even if it has been demonstrated to be efficient, the empirical correction 10 used here does not allow us to control the signal ultimately extracted from the altimetric measurement. Since fairly recently, better control of the corrected signal has been possible using a new kind of model-based correction. This suggests that the results presented before could be improved. However, as the principle of the OSSE was to consider such a model output as the reference signal, it is not possible for us to test 15 this new kind of correction. The impact of such a MOG2D model-based correction will be discussed in Sects. 4.2 and 5.2 .

Finally, the correction of the HF LW signal in altimetry data raises some important questions. Which HF signal is observed by altimeters? Can we correct it without altering other signals? Which signal is ultimately restored by the AOS? When extracting the aliased HF signal from altimetry measurements, can we use it to estimate the total surface signal, which is useful for many other studies? These are some of the many questions we have tried to answer in the following sections.

\subsection{The altimetric observing system's ability to restore the HF LW signal}

\subsubsection{Temporal aliasing effect}

25 Normal and inevitable temporal aliasing of the HF signal is induced by the revisit frequency of the measurements which is 10 days at best with TP and J1. While these two satellites allow us to observe signals accurately with intervals of greater than 20
OSD

4, 571-622, 2007

\section{Altimetric data in the Mediterranean Sea}

M.-I. Pujol et al.

\section{Title Page}

Abstract Introduction

Conclusions References

Tables Figures

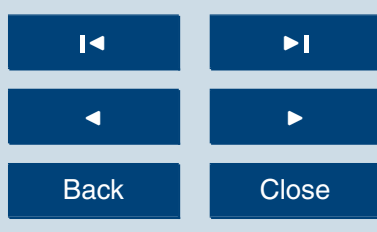

Full Screen / Esc

Printer-friendly Version

Interactive Discussion 
days from along-track data, this limit is modified when the signal from gridded maps is considered. In fact, the gridded product results from the combination of different satellites with different revisit frequencies. Moreover, the mapped signal is altered by the smoothing effect inherent to the mapping procedure.

5 In order to determine the limit frequency restored from altimetric maps, we compared the frequency spectrum of both the MOG2D reference signal and the signal restored using the OSSE_600 (Sect. 3.1). Choosing to use the OSSE_600 signal allowed us to limit the spatial aliasing effect as shown in the next section. However, the same study undertaken with OSSE_250 led to similar results (not shown).

10 Both the reference signal and the OSSE_600 signal frequency spectrum are given in Fig. 5.

We first remind the reader that intervals of less than 14 days are not accessible from OSSE_600 (weekly maps, Sect. 3.1). The comparison of the two spectra clearly reveals that over 14 days, most of the signal is considerably under-estimated by the 15 OSSE_600 signal. The exact limit of the frequency which is not under-estimated from the OSSE_600 signal is difficult to identify. However, it can be considered that it is nearly $40^{-1}-30^{-1}$ days $^{-1}$. The power of the reference MOG2D signal for the frequencies higher than 35 days $^{-1}$ is nearly $9.3 \mathrm{~cm}^{2}\left(2.36 \mathrm{~cm}^{2}\right.$ between $35^{-1}$ and $14^{-1}$ days $\left.{ }^{-1}\right)$. It falls to nearly $0.36 \mathrm{~cm}^{2}$ for the OSSE_600 signal. Conversely, the lower frequency sig20 nal is slightly overestimated in the OSSE_600 signal. In fact, the power of this signal for frequencies lower than $35^{-1}$ days ${ }^{-1}$ is $2.05 \mathrm{~cm}^{2}$. It is $1.96 \mathrm{~cm}^{2}$ for the reference MOG2D signal.

While the smoothing of the HF signal by the mapping procedure is inevitable, the importance of this smoothing as observed here must not be generalised to all existing 25 altimetric mapped products. In fact, the HF signal reduction depends on the different characteristics of the mapping procedure (number of satellites merged and their characteristics, frequency of the maps generated, correlation scales considered in the OA interpolation procedure, etc.). However, a study undertaken over the period [October 2002-September 2005] where a four-satellite configuration was possible (with
OSD

4, 571-622, 2007

\section{Altimetric data in the Mediterranean Sea}

M.-I. Pujol et al.

\section{Title Page}

Abstract Introduction

Conclusions References

Tables Figures

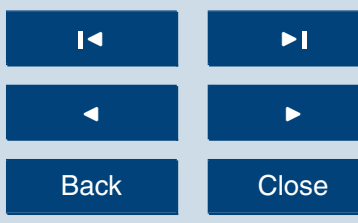

Full Screen / Esc

Printer-friendly Version

Interactive Discussion 
ERS-2/EN, TP, J1 Geosat Follow On) showed that the difference between a two or four-satellite configuration was insignificant, since with four satellites the restored frequency limit was also nearly $40^{-1}-30^{-1}$ days $^{-1}$.

Finally, it can be considered that signals with intervals of less than 30 days are not 5 accessible from the AOS mapped data as generated in Sect. 2.2. However, as an accurate estimate of this signal is given by the MOG2D model, we can estimate its contribution to the total signal, as described in Sect. 5 .

\subsubsection{Spatial aliasing}

Spatial noise induced by the signature of the HF LW signal on along-track data is identified when analysing the spatial structure of maps of the OSSE_250 signal. Here, this signal was decomposed in EOF. The spatial component of the first four modes obtained is shown in Figs. 4 and 6.

As mentioned before (Sect. 3.3), two modes (the first and fourth) characterise the real surface signal. However they are altered due to the noise signal. The main part of this noise signal is clearly identified with the second and third modes. These two modes account for respectively $7.9 \%$ and $5.8 \%$ of the variance. They clearly show a signal variability associated with the alternation of positive/negative vertically-oriented bands. The fact that this vertical-banded signal was not identified by the analysis of the MOG2D reference signal, leads us to suppose that it should not be interpreted sampling and mapping of the HF LW signal.

The spatial structure of the error signal revealed the characteristic sampling of the HF LW signal by the different altimeters, especially by ERS/EN. An example of this particular sampling will be given in Sect. 4.1, Fig. 9. The signature of the along-track
OSD

4, 571-622, 2007

\section{Altimetric data in the Mediterranean Sea}

M.-I. Pujol et al.

\section{Title Page}

Abstract Introduction

Conclusions References

Tables Figures

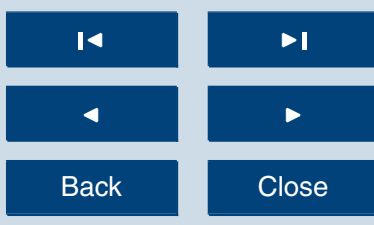

Full Screen / Esc

Printer-friendly Version

Interactive Discussion correction applied and the ineffectiveness of the mapping procedure in considering the along-track signal and propagating it in space in order to obtain spatially homogeneous maps. In fact, as the signal correlation scales used for the OA process have been 
optimised for the restitution of the mesoscale signal (Pujol and Larnicol, 2005), they limit the OA's ability to propagate the LW signal. The reduction of the error signal thus implies the direct reduction of the inter-track bias in order to limit residual errors due to the signal's low spatial projection. Here the solution proposed was to consider more 5 effectively the parameterisation of the empirical correction used (Le Traon et al., 1998) (Sect. 2.2) in order to adjust it more closely to the characteristics of the signal in the Mediterranean Sea.

The spatial distribution of the error signal was taken into account in particular, leading to a re-estimate of the spatial domain of the data selection. In this way, instead of a 10 range of $250 \mathrm{~km}$, we applied a domain selection of $600 \mathrm{~km}$ that corresponded more or less to the correlation scale of the spatial aliasing error signal described earlier. In fact, $\sim 600 \mathrm{~km}$ corresponds to the thickness of a coupled positive/negative band resulting from the sampling/mapping of the HF LW signal (visible on the second and third modes in Fig. 6). The OSSE signal thus generated was noted as OSSE_600 (Sect. 3.1).

15 The results obtained are shown in Fig. 7. The EOF decomposition of the OSSE_600 signal revealed four main modes.

The first is explained by the mean basin-wide variability, slightly higher in the eastern basin. Here this mode accounts for nearly $71.1 \%$ of the signal variance which is much higher than the part of the variance accounted for by this mode in the OSSE_250 signal.

Moreover, it should be noted that the spatial structure of this mode is clearer in the OSSE_600 signal. As highlighted before, this mode must be coupled with the second mode that is explained by the eastern/western basin balance. Similarly to the first mode, accounting for $4.8 \%$ of the variance, this mode represents a greater part of the signal than observed for the OSSE_250 signal. This phenomenon is explained by the reduction of the error signal that also slightly alters this mode's spatial structure. Moreover, the spatial structure of the second mode corresponds better to its equivalent in the reference signal (Fig. 2), since the signal in the lonian Sea is weaker. However, the next two modes seem to complete the variability in this basin. The third mode accounts for nearly $3.2 \%$ of the signal variance. It highlights the surface variability in

\section{OSD}

4, 571-622, 2007

\section{Altimetric data in the Mediterranean Sea}

M.-I. Pujol et al.

\section{Title Page}

Abstract Introduction

Conclusions References

Tables Figures

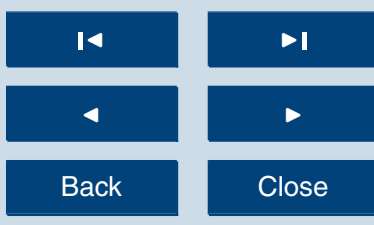

Full Screen / Esc

Printer-friendly Version

Interactive Discussion 
the Adriatic Sea and in the north-eastern part of the Ionian Sea. On the other hand, the fourth mode completes the variability in the rest of the Ionian Sea and is clearly in contrast to part of the activity in the Levantine Sea. This fourth mode accounts for $2.2 \%$ of the variance.

$5 \quad$ Finally, readjusting the empirical correction led to great results in terms of reducing the errors of the aliased signal observed in the restored signal. However it did not lead to the total elimination of this signal since some residual error signals still alter the spatial structure of the modes observed. It clearly appears in the third mode, emphasising some satellite tracks (see for instance the Levantine basin). However,

10 this residual error signal is now too weak to be explicitly accounted for by a dedicated mode.

The results obtained with the empirical correction parameterised to a range of $600 \mathrm{~km}$ seem to indicate that this correction should be applied in the AOS in order to limit the error signal linked with the aliasing effect of the HF LW signal. However, this 15 empirical correction does not allow us to control the signal which is ultimately extracted. This problem should be resolved using a new kind of correction, which is better able to consider the physics of the surface due to the ability of the numerical models. This kind of correction, mentioned before, consists in directly extracting the HF LW signal from the along-track data, and identifying this signal from the numerical model. The success of such a correction, based on the MOG2D model, has already been demonstrated by Carrère et al. $(2007)^{1}$ for the global ocean, or by Manggiaroti and Lyard (2007) for the Mediterranean Sea. However, the latter authors only focused on interannual signal restitution. The ability of this correction to improve the accuracy of the HF signal $\left(>30^{-1}\right.$ days $\left.^{-1}\right)$ restored with the AOS will be discussed in Sect. 4.2.

\section{Application to real data}

Previously, the OSSE allowed us to identify specific problems linked to the HF LW surface signal aliasing effect induced by sampling/mapping the signal in the AOS. The

OSD

4, 571-622, 2007

Altimetric data in the Mediterranean Sea

M.-I. Pujol et al.

Title Page

Abstract Introduction

Conclusions References

Tables Figures

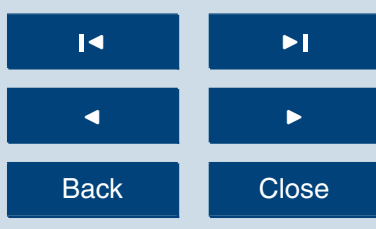

Full Screen / Esc

Printer-friendly Version

Interactive Discussion 
next sections are devoted to the analysis of the real signal restored with the SLA maps in the Mediterranean Sea. The importance of this noise signal and different solutions to minimise it were analysed.

\subsection{Importance of the residual errors in the HF signal}

5 As was previously identified with the OSSE_250 signal, we can observe in real SLA maps some noise related to the sampling and mapping of the HF LW signal. This noise is highlighted by the EOF decomposition of the HF signal restored with maps of SLA. Here, the altimetric mapped data considered come from the AOS_250 data set, described in Sect. 2.2. Only the HF component of the SLA signal was considered.

10 This signal was extracted applying a Loess time filter with a 30-day cut-off period. This 30-day limit was chosen with reference to the results obtained in Sect. 3.4.1. It allows us to highlight the aliasing linked to the sampling/mapping of the HF LW signal since intervals of less than 30 days represent the part of the signal which is poorly restored. Moreover, this filtering limits the signal's signature at lower frequencies, which 15 is a strong component of the SLA signal (Larnicol et al., 2002; Pujol and Larnicol, 2005) and can completely mask the error signal we attempted to identify using EOF decomposition. The spatial component of the first five modes deduced from the EOF decomposition of the HF $\left(>30^{-1}\right.$ days $\left.^{-1}\right)$ SLA signal are shown in Fig. 8.

The first four modes have the same characteristics as the ones deduced from the

OSSE_250 signal (Sect. 3.4.2, Figs. 4 and 6). The first and third modes represent the signature of the HF LW signal: a basin-wide dominant variability more pronounced in the eastern basin, shown here with the first mode accounting for $21 \%$ of the signal variance; and a balance between the western and eastern basin, here identified with the third mode that accounts for $3.1 \%$ of the variance. Both these modes have a tempo-
OSD

$4,571-622,2007$

\section{Altimetric data in the Mediterranean Sea}

M.-I. Pujol et al.

\section{Title Page}

Abstract Introduction

Conclusions References

Tables Figures

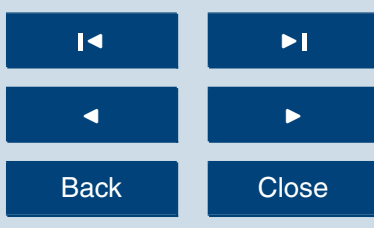

Full Screen / Esc

Printer-friendly Version

Interactive Discussion stronger variability in autumn/winter. Of course, this signal's amplitude as observed from weekly altimetric maps is essentially weaker than in reality (which, for these frequencies, is estimated with the MOG2D model (Sect. 3.2)) since we have seen that 
the HF LW signal restored after along-track sampling and the mapping procedure is significantly underestimated for frequencies higher than $30^{-1}$ days ${ }^{-1}$ (Sect. 3.4.2).

Moreover, the spatial structure of the first and third modes also show signals with small spatial scales, more pronounced in the eastern basin, and representative of a 5 spatial aliasing effect resulting from the sampling/mapping procedures. For the third mode, the noise has the same vertical-banded structure as previously highlighted with the OSSE_250 signal. Most of this noise is identified in both the second and fourth modes (Fig. 8). As observed before with the OSSE_250 signal, the variance explained by each of these two modes is as considerable as the third mode, with respectively $103.4 \%$ and $2.8 \%$ of the variance accounted for.

For the first mode, the noise signal that alters the spatial structure highlights the $\mathrm{TP} / \mathrm{J} 1$ tracks. The main part of this noise is shown by the fifth mode that accounts for nearly $2.6 \%$ of the variance (Fig. 8). The reader will note that such a spatially-structured signal does not clearly appear in the OSSE_250 signal (Sect. 3). This seems to indicate that this error signal does not only involve HF LW barotropic sampling/mapping difficulties. The source of this error signal is discussed in Sect. 4.3.

It is important to note that with respect to the total SLA signal, the variability linked to these error signals is very low. However, in some cases, their signature is directly visible on SLA maps. An example is shown in Figs. 9a and b. It represents the EN along-track data collected between 18 February and 3 March 2004 and the SLA map generated for 25 February 2004 from these data (also combined with $\mathrm{J} 1$ data collected over the same period). The along-track data clearly show the specific "vertical-banded" structure resulting from the altimetric sampling of the HF LW signal. The SLA measured at the beginning of the period was strongly negative. It is visible along bold tracks, centred around $17^{\circ} \mathrm{E}$ and $25^{\circ} \mathrm{E}$. Conversely, at the end of the period SLA were considerably positive as seen in fine tracks centred around $21^{\circ} \mathrm{E}$ and $29^{\circ} \mathrm{E}$. Whereas an empirical correction (Le Traon et al., 1998) was applied to the data to reduce this intertrack bias, and whereas the mapping process should also smooth this signal in order to obtain a homogeneous map, we can see on the gridded map obtained (Fig. 9b) that
OSD

4, 571-622, 2007

\section{Altimetric data in the Mediterranean Sea}

M.-I. Pujol et al.

Title Page

Abstract Introduction

Conclusions References

Tables Figures

I

14

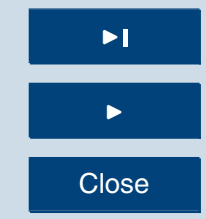

Back

Full Screen / Esc

Printer-friendly Version

Interactive Discussion

EGU 
the signature of these vertical bands still remain, highlighting the limits of the correction applied and of the mapping process.

The reader should note that this example is the strongest observed over a 12-year period. The limit of the correction for this example comes from both the large amplitude

5 of the HF event over the eastern basin, and also from the lack of some EN tracks since some data were rejected by the different selection/validation procedures applied to the data before mapping. This lack of data limits the impact of the empirical correction as it was parameterised.

Even if in the end, this error signal contributes little to the total variance of the total 10 SLA signal, such a signature on SLA maps has enabled us to consider more carefully the correction of the aliasing effect linked with the HF LW signal.

The OSSE study showed us that most of these errors can be removed using a better adjustment of the empirical correction used. However, as mentioned earlier, a new correction, which takes into account more carefully the physical characteristics of the 15 HF surface signal, was also tested. This correction, based on the MOG2D model output and described by Carrère et al. (2007) ${ }^{1}$ was shown to improve the restitution of the interannual signal in the Mediterranean Sea (Mangiarotti and Lyard, 2007). Here we focus on the impact of the MOG2D model-based correction on the restitution of the HF signal.

\section{4.2 Contribution of the MOG2D model-based correction}

The MOG2D model's contribution to reducing spatial aliasing errors in the Mediterranean Sea was evaluated by analysing the HF signal restored with the AOS_MOG2D data set (Sect. 2.2). As done before, the HF $\left(>30^{-1}\right.$ days $\left.^{-1}\right)$ component of the SLA was decomposed in EOF. The first four modes obtained (spatial component only) are shown in Fig. 10.

Two of these modes, the first and fourth, clearly show the characteristics of the real HF LW signal with a basin-wide variability more pronounced in the eastern part (first mode, accounting for $18.5 \%$ of the variance) and modulated with an eastern/western

OSD

4, 571-622, 2007

Altimetric data in the Mediterranean Sea

M.-I. Pujol et al.

\section{Title Page}

Abstract Introduction

Conclusions References

Tables Figures

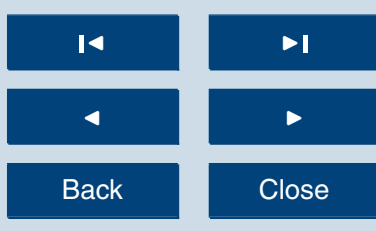

Full Screen / Esc

Printer-friendly Version

Interactive Discussion 
basin balance (fourth mode, accounting for $2.5 \%$ of the variance).

However, theses two modes are strongly associated with the LW noise signal. In fact, it is clear that the first mode is also explained by the part of the noise signal highlighting the TP/J1 tracks. Contrary to the decomposition observed from maps of 5 SLA corrected with the empirical method alone (Sect. 4.1), here this noise mode is entirely restored by this first mode (it was previously characterised by the fifth mode; Fig. 8). Conversely, even though the fourth mode is also strongly affected by the LW error signal, the main part of this error signal is shown by both the second and third modes (explaining respectively $3.7 \%$ and $3.1 \%$ of the variance). They correspond to 10 the vertical-banded error signal previously observed with the second and fourth modes characteristic of the HF component of the SLA corrected with the empirical method alone (Sect. 4.1, Fig. 8).

The role of the MOG2D model-based correction in the global ocean has already been demonstrated by Carrère et al. (2007) ${ }^{1}$. The authors showed that this correction clearly contributed to reducing the variance of the error signal over the entire frequency spectrum, thus leading to a better restitution of the total SLA signal than that obtained with the empirical correction alone. The contribution of the MOG2D model-based correction over the Mediterranean Sea only has been studied by Mangiarotti and Lyard (2007). The authors focused on the interannual signal only and showed that it is better 20 restored using this correction.

Conversely, the results obtained in this paper seem to indicate that the MOG2D model contributed not to reducing the error signal linked with sampling/mapping of the HF LW signal, but rather to reducing the role of the real HF LW signal reconstructed with maps of SLA. In fact whereas the residual HF LW signal explained nearly $24 \%$ of the variance when the empirical correction was considered (Sect. 4.1, Fig. 9), with the MOG2D model-based correction, this signal accounted for only $21 \%$ of the variance, also considering the noise signal that highlighted the TP/J1 tracks. As a consequence, this led to a larger share of the variance being explained by the error signal.

Many explanations could account for the contradictory results obtained.
OSD

4, 571-622, 2007

\section{Altimetric data in the Mediterranean Sea}

M.-I. Pujol et al.

\section{Title Page}

Abstract Introduction

Conclusions References

Tables Figures

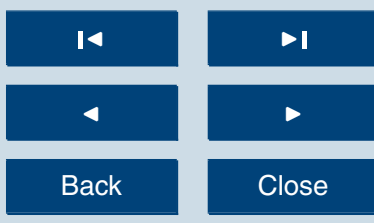

Full Screen / Esc

Printer-friendly Version

Interactive Discussion 
First it is important to note that, contrary to the view of the authors cited earlier, the analysis focused on the HF signal $\left(>30^{-1}\right.$ days $\left.^{-1}\right)$ that has been demonstrated as the hardest part of the signal to restore, and thus concentrates many kinds of error signal.

The poor results obtained here with the MOG2D model also suggest that the er-

5 ror signal observed does not involve the barotropic signal alone. In fact, while the barotropic signal is the main component of HF surface variability at these latitudes (Fukumory et al., 1998), it does not represent all of the signal, especially when considering lower frequencies than $20^{-1}$ days $^{-1}$. As a consequence, this part of the signal is not included in the MOG2D output and therefore, aliasing errors induced by this signal 10 cannot be reduced using the barotropic model's contribution.

It is also important to note that the role of MOG2D was considered for frequencies higher than $20^{-1}$ days $^{-1}$ only, with reference to the parameterisation adopted in the global ocean (Carrère et al., $2007^{1}$ ). However, it was clearly shown that in the Mediterranean Sea, the signal with frequencies up to $40^{-1}-30^{-1}$ days ${ }^{-1}$ is aliased. This sug15 gests that perhaps a better parameterisation of the MOG2D model-based correction could improve the results obtained.

Moreover, as discussed before, the signature of the satellite tracks on maps of SLA also seems to reveal the difficulty the mapping procedure has in propagating the LW signal. This phenomenon must be linked with the parameterisation of the method, optimised for mesoscales rather than for LW signal reconstruction (Pujol and Larnicol, 2005).

Finally, as the MOG2D model-based correction needed to be completed with an empirical correction to be more efficient (Carrère et al., $2007^{1}$ ), and as a reparameterisation of the correction for the Mediterranean Sea alone involves a significant investment, even if the optimum results would be obtained with this model-based correction, we chose to reduce the aliasing error signal identified using the empirical method alone. In fact, we previously demonstrated that an easy readjustment of the method would substantially improve the results obtained.
OSD

4, 571-622, 2007

\section{Altimetric data in the Mediterranean Sea}

M.-I. Pujol et al.

\section{Title Page}

Abstract Introduction

Conclusions References

Tables Figures

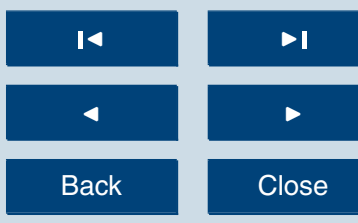

Full Screen / Esc

Printer-friendly Version

Interactive Discussion 
We saw in the OSSE study that improved consideration of the unique characteristics of the signal in the Mediterranean Sea for parameterising the empirical correction clearly improves this correction's efficiency. Here, the new parameterisation tested 5 consisted in enlarging the size of the spatial domain considered from $250 \mathrm{~km}$ to $600 \mathrm{~km}$ (Sect. 3.4.2). This new parameterisation was applied in the AOS and the signal thus obtained was noted as AOS_600 (Sect. 2.2). The results obtained with this signal are described below.

An example of the results obtained with this new parameterisation is given in Fig. 9c. 10 It corresponds to the map generated for 25 February 2004 from EN along-track data collected between 18 February and 3 March and shown in Fig. 9a. The same map generated while applying the $250 \mathrm{~km}$ range parameter for the empirical correction is shown in Fig. 9b. It clearly demonstrates that the error signal we tried to reduce was largely reduced with the $600 \mathrm{~km}$ range parameterisation.

15 An EOF decomposition of the HF signal contained in maps generated while applying the $600 \mathrm{~km}$ range parameterisation (not shown) showed that these vertical-banded errors, highlighted by the second and fourth mode of variability when the $250 \mathrm{~km}$ range was used (Sect. 4.1, Fig. 8), are now absent, on account of the real signal (represented by first and third modes in Fig. 8) which is also less noisy than previously. Now the two 20 representative modes account for respectively $22.7 \%$ (mode revealing the basin-wide variation, greater in the eastern basin) and $3.3 \%$ of the variance (mode revealing the eastern/western balance).

However, the new parameterisation of the empirical correction does not correct all of the aliasing error signal. In fact, the mode highlighting the TP/J1 tracks (fifth mode 25 in the signal decomposition corrected with the $250 \mathrm{~km}$ range parameter; Sect. 4.1, Fig. 8) is still present in the signal corrected with the $600 \mathrm{~km}$ range parameter, where it represents the third mode of variability and accounts for nearly $2.5 \%$ of the variance. The persistence of this error signal reveals its complex origin, involving LW surface
4, 571-622, 2007

\section{Altimetric data in the Mediterranean Sea}

M.-I. Pujol et al.

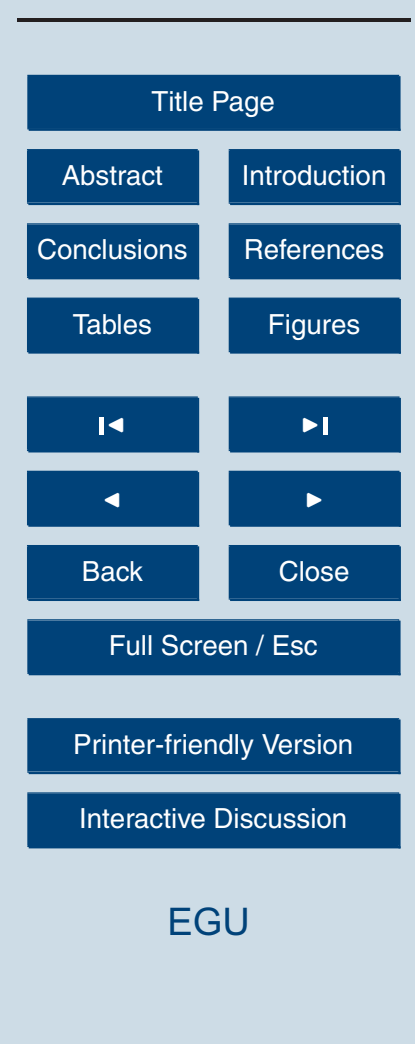


variability (barotropic and non-barotropic components), its along-track sampling and its mapping. Here this signal seems to be explained by the signal's higher variability in the TP/J1 inter-track due to the lack of more frequent data in these areas for estimating the signal. A similar EOF analysis of the HF signal was carried out over the period 5 [2000-2005] when the SLA signal could be restored by merging the information from three or four different altimeters (not shown). It revealed that this error signal strongly decreased since no significant signature was observed. This result tends to confirm that such an error signal results from the combination of satellite spatial coverage and the ability of the mapping procedure to extend the signal far beyond the track location.

10 The reader will note that the improved correction of the signal was obtained simply by changing the size of the selection domain. The variance associated with the inter-track bias error signal was unchanged. In fact, we consider that the values currently used $\left(9 \mathrm{~cm}^{2}\right.$ for T/P and $\mathrm{J} 1$, and $15 \mathrm{~cm}^{2}$ for ERS1/2 and EN) accurately represent this signal in the Mediterranean Sea. However, a sensitivity study was undertaken to evaluate the 15 impact of these values on the inter-track bias correction. It showed the largely weaker sensitivity of the results to this parameter rather than to the size of the domain defined. Moreover, it was shown that the HF LW signal was not entirely uniform over the basin (Sect. 3.2), suggesting that better results could be obtained when using a spatially variable variance associated with along-track bias, rather than spatially constant as is currently the case.

\section{Merging MOG2D and altimetry data to obtain an estimate of the total surface variability}

The results obtained before clearly showed that the SLA maps were unable to restore the total surface signal. In fact it was demonstrated that signals with frequencies higher than $40^{-1}-30^{-1}$ days ${ }^{-1}$ were strongly attenuated in the reconstructed altimetric signal (Sect. 3.4.1). On the other hand, barotropic variability, the main component of HF surface variability at these latitudes (Fukumori et al., 1998), was relatively well repro-

OSD

4, 571-622, 2007

Altimetric data in the Mediterranean Sea

M.-I. Pujol et al.

\section{Title Page}

Abstract Introduction

Conclusions References

Tables Figures

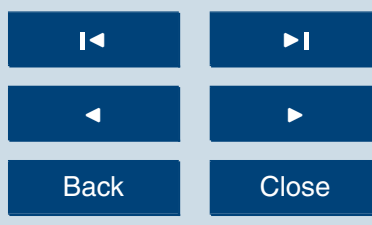

Full Screen / Esc

Printer-friendly Version

Interactive Discussion 
duced by numerical models. As the MOG2D model capabilities were demonstrated (Lyard and Roblou, 2003; Carrère and Lyard, 2003), it was used in conjunction with altimetry data to estimate the total surface signal in the Mediterranean Sea.

\subsection{Methodology}

5 The method used consisted in combining both complementary signals: respectively the LF component of surface variability restored with the AOS, and the HF component modelled by the MOG2D model. The weekly altimetric maps (Sect. 2.2) were interpolated daily (linear interpolation) and then combined with the daily mean of the 6-h output of the MOG2D model (Sect. 2.1). Both LF altimetric signal and HF MOG2D signal were obtained by applying a Lanczos low-pass filter.

A first test consisted in analysing the impact of the different HF LW signal corrections discussed earlier. Three different combinations were therefore compared. They consisted in combining the total MOG2D signal successively with the LF component of the AOS_250, AOS_600 and AOS_MOG2D signals. The LF component was consid5 ered as frequencies lower than $30^{-1}$ days $^{-1}$ with reference to the results presented in Sect. 3.4.1. The three data sets thus obtained were noted as AOS_250_LF30+MOG2D, AOS_600_LF30+MOG2D and AOS_MOG2D_LF30+MOG2D. The comparison of the results obtained with these three different combinations is given in Sect. 5.2.1.

Subsequently, the sensitivity of the results to the filter cut-frequency applied to the different data sets to be combined was analysed. In this way, different combined data sets were generated.

As a similar combination undertaken by Lyard and Roblou (2003) from the PSY2-v1 MERCATOR model showed that the LF component of the MOG2D signal significantly improved the results obtained, we first tested this signal's contribution. Two different combinations were used. They combined the LF component of the AOS_MOG2D signal with respectively the total MOG2D signal and the HF component of the MOG2D signal. Here the LF AOS_MOG2D signal and the HF MOG2D signal were filtered with a $30^{-1}$ days $^{-1}$ cut-frequency with reference to the results described in Sect. 3.4.1.

Altimetric data in the Mediterranean Sea

M.-I. Pujol et al.

\section{Title Page}

Abstract Introduction

Conclusions References

Tables Figures

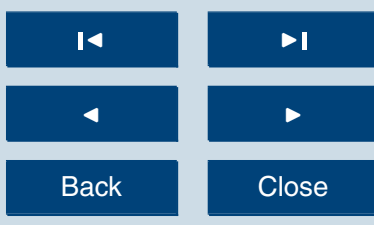

Full Screen / Esc

Printer-friendly Version

Interactive Discussion 
The combinations thus obtained were noted as AOS_MOG2D_LF30+MOG2D and AOS_MOG2D_LF30+MOG2D_HF30. The comparison of these two combinations is given in Sect. 5.2.2.

Finally, a third experiment was undertaken in order to test the sensitivity of 5 the results to the cut-frequency used to extract the altimetric LF component. In this way five combinations were compared. They consisted in combining the total MOG2D signal with the LF component of the AOS_MOG2D signal. Five cutfrequencies were applied: $20^{-1}, 30^{-1}, 40^{-1}, 60^{-1}$ and $80^{-1}$ days $^{-1}$. The different combinations thus obtained were noted as AOS_MOG2D_LF20+MOG2D, 10 AOS_MOG2D_LF30+MOG2D, AOS_MOG2D_LF40+MOG2D, AOS_MOG2D_LF60+ MOG2D and AOS_MOG2D_LF80+MOG2D. The results obtained with these five combined signals are given in Sect. 5.2.3.

The accuracy of the different combinations generated was estimated by comparing them to different daily mean tide gauge data obtained over the 12-year period [199315 2004] and given in Sect. 2.3.

\subsection{Combined signal and tide gauge comparison}

\subsubsection{Sensitivity to the HF LW signal correction applied}

As the sensitivity of the different HF LW signal corrections was discussed previously (Sect. 4) for the restored HF signal component, here three different combinations were compared to the tide gauge data, only considering the LF signal. In this way both tide gauge data and the combined signal were filtered with a 20-day low-pass filter. The results obtained from comparing the LF component of the AOS_250_LF30+MOG2D, the AOS_600_LF30+MOG2D and the AOS_MOG2D_LF30+MOG2D signals with tide gauge data are given in Table 2 .

25 As expected, they showed that the poorest results were obtained when the altimetric signal was corrected by applying the empirical correction with a $250 \mathrm{~km}$ range parameter. The mean correlation between tide gauge data and AOS_250_LF30+MOG2D

OSD

4, 571-622, 2007

Altimetric data in the Mediterranean Sea

M.-I. Pujol et al.

\section{Title Page}

Abstract Introduction

Conclusions References

Tables Figures

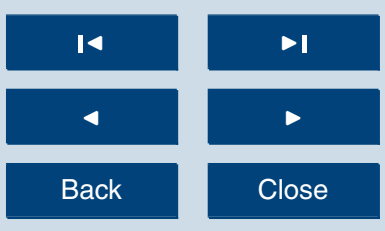

Full Screen / Esc

Printer-friendly Version

Interactive Discussion 
combined data was nearly 0.89 . The variability of the difference between the two data sets represents nearly $27 \%$ of the tide gauge signal variability.

The best results were obtained with both the MOG2D model-based and the empirical correction with a $600 \mathrm{~km}$ range parameter. In fact, the mean correlation with the tide 5 gauge data was nearly 0.9 for the two data sets and the error of the signal represented nearly 25 to $26 \%$ of the signal variability.

However, the differences between the mean results remained very low. They were greater when considering each station independently. In fact, locally the impact of the MOG2D model-based correction led to an increase in the correlation with the tide 10 gauge signal of 0.1 and a reduction in error representing more than $10 \%$ of the signal variability. This was true for instance with the Imperia, Livorno and Ortona_1 stations where the MOG2D model-based correction clearly improved the signal restitution with respect to the empirical correction with the $250 \mathrm{~km}$ range parameterisation.

Conversely, few stations revealed that the empirical correction with a range of $250 \mathrm{~km}$ 15 led to the best results. This was true for the Ancona, Crotone_2, Palinuro_4, Portotorres and Salerno_2 stations. However, the improvement remained lower than the one observed locally with the MOG2D model-based correction. In fact, the empirical correction $(250 \mathrm{~km}$ range) increased the correlation with the tide gauge signal by only 0.01 to 0.03 for the majority of the stations concerned. The improvement was significant only for the Salerno_2 station where an increase of nearly 0.08 of the correlation was observed between the two combined signals. However, with nearly 0.69 of correlation for the best combination, it was also at this station that the poorest correspondence between combined and tide gauge signals was observed, which can be explained by the difficulty the AOS and the MOG2D signal have in accurately restoring the signal at 25 the station location.

Some stations revealed that the empirical correction with the $600 \mathrm{~km}$ range parameterisation led to the best results. However, the difference with the MOG2D modelbased correction was generally low. They were significant for only two stations. At the Ortona_2 station, the empirical correction (600 km range) increased the correlation
OSD

4, 571-622, 2007

\section{Altimetric data in the Mediterranean Sea}

M.-I. Pujol et al.

\section{Title Page}

Abstract Introduction

Conclusions References

Tables Figures

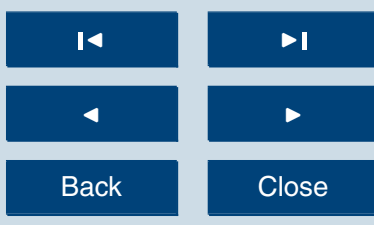

Full Screen / Esc

Printer-friendly Version

Interactive Discussion 
with the tide gauge signal of 0.6 with respect to the MOG2D model-based correction. Likewise, the improvement of the correlation was nearly 0.9 at the Otranto_2 station.

The great variability of the results obtained can be explained by the complexity of the correction of the HF LW signal in the Mediterranean Sea. As the empirical correction 5 needs to consider the signal in a spatial bubble, it limits the consideration of local phenomenon, especially with the $600 \mathrm{~km}$ range parameterisation. Moreover, the quality of this correction is closely connected to the quality of the measurement, particularly sensitive in coastal areas. Conversely, the MOG2D model-based correction should make better allowance for local coastal phenomenon. However, this facility remains 10 limited by the spatial resolution of the atmospheric forcing used and of the model grid.

The results obtained here are consistent with the ones given by Carrère et al. (2007) ${ }^{1}$ or Mangiarotti and Lyard (2007) that demonstrated the impact of the MOG2D modelbased correction on the LF signal. However, the sensitivity to the results remains very low for a large number of the stations considered.

15 Finally, as the AOS_MOG2D or AOS_600 signals led to similar results, it was decided to pursue the study with the MOG2D model-based corrected signal. In fact, as mentioned earlier, this correction allows better control of the corrected signal. Moreover, many of the residual errors previously identified (Sect. 4.2) in the HF component of the AOS signal when applying this correction have been removed here by the low-pass filtering of the AOS signal.

\subsubsection{Impact of the HF MOG2D signal component}

As Lyard and Roblou (2003) previously showed that the LF MOG2D signal could contain a complementary signal with respect to the PSY2v1 MERCATOR model, the complementarities of this signal with respect to AOS were tested. The two com-

bined signals AOS_MOG2D_LF30+MOG2D and AOS_MOG2D_LF30+MOG2D_HF30 were therefore compared. The results are given in Table 3.

They clearly showed that taking into account the LF component of the MOG2D signal significantly improved the results obtained. In fact the mean correlation between

OSD

4, 571-622, 2007

Altimetric data in the Mediterranean Sea

M.-I. Pujol et al.

Title Page

Abstract Introduction

Conclusions References

Tables Figures

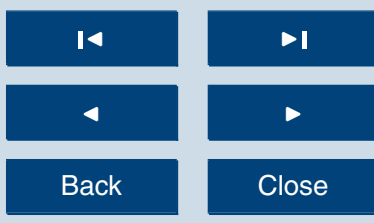

Full Screen / Esc

Printer-friendly Version

Interactive Discussion

EGU 
the tide gauge data and the AOS_MOG2D_LF30+MOG2D signal was 0.83 . It fell to 0.80 for the combinations involving the MOG2D_HF30 signal. The individual analysis of each tide gauge considered revealed that the LF MOG2D component improved the results for most of the stations considered. These results correspond to the observation 5 previously made by Lyard and Roblou (2003). The authors undertook a similar combination from PSY2v1 and MOG2D dynamic models. They observed that the LF MOG2D component effectively contributed to better restitution of the total surface signal by combining the two complementary models. As highlighted by the previous authors, these results were unexpected since the LF MOG2D component was unrealistic (Carrère, 10 2003). However, the information provided by the model for frequencies from $30^{-1}$ to nearly $60^{-1}$ days $^{-1}$ is not negligible, and on a localised basis can significantly add to the AOS signal that restores it poorly (Sect. 3.4). This phenomenon was quite clearly visible for the Civitavecchia station (Fig. 11) where $40^{-1}-30^{-1}$ days ${ }^{-1}$ frequencies of variability could be clearly observed in the tide gauge and AOS_MOG2D_LF30+MOG2D 15 signals, whereas it was attenuated in the AOS_MOG2D_LF30+MOG2D_HF30 signal (see 2003 for instance).

However, some considerable bias between the combined signal and the tide gauge was observed in the HF variability regardless of the MOG2D signal considered. Some bias in HF variability can be explained by aberrant data in the tide gauge set or the 20 inability of the MOG2D model to reproduce some specific events, either because they did not correspond to the physical signal restored by the model, or because the spatial resolution of the model and atmospheric forcing which were used limited its abilities.

Other considerable biases on the LF component can also be observed. An example is given in Fig. 11 for the Civitavecchia station, where some inconsistency in seasonal 25 variability can clearly be seen. In fact, a bias in the phase of the summer/autumn SLA increase was quite visible in 2000 and 2001. the SLA increase appeared nearly three weeks earlier in the combined signal than in the tide gauge signal. This kind of bias was observed for other stations located along the eastern Tyrrhenian coast (e.g. Livorno and Messina in 2002, Naples in 2000) and around the Sicilian coast (e.g. Porto Empedocle

\section{OSD}

4, 571-622, 2007

\section{Altimetric data in the Mediterranean Sea}

M.-I. Pujol et al.

\section{Title Page}

Abstract Introduction

Conclusions References

Tables Figures

I

14

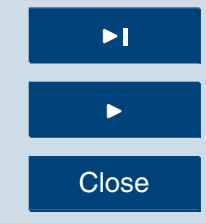

Full Screen / Esc

Printer-friendly Version

Interactive Discussion 
in 2002; Reggio Calabria in 2001 and 2002). This phenomenon could be explained by the limited ability of the AOS (which is constrained by altimetric spatial/temporal sampling) to reproduce specific local events accurately.

\subsubsection{Sensitivity to the altimetry data filtering}

5 A second sensitivity experiment was undertaken to consider different low-pass filter cutting frequencies for the altimetric signal. Five different cutting frequencies were tested: $20^{-1}, 30^{-1}, 40^{-1}, 60^{-1}$ and $80^{-1}$ days $^{-1}$. The comparison of the combined signal (LF altimetric component + total MOG2D signal) with the tide gauge data is summarised in Table 4.

10 The mean correlation between the combined and tide gauge signals revealed that the best results were obtained when filtering the altimetric signal with a 20-30 day filter. However the sensitivity of the results is insignificant, especially between 20 and 40 days. In fact the mean correlation obtained for these filters is nearly 0.83 . Moreover, applying a 40-day filter proves more successful in reducing the variability of the misfit signal. However, here again, the sensitivity between the 30 to 60 day filter is insignificant since the results are nearly 4.5 to $4.52 \mathrm{~cm}$ for each filter.

As underlined before, analysing each tide gauge station individually revealed greater variability in the results obtained.

Some stations were rather insensitive to the filter applied. This was the case for 20 instance with the Catania_2, Imperia, Livorno, Napoli_2, Otranto_1, Salerno_1 and Valencia stations that reported a variation in the correlation between the tide gauge and the combined signal of less than 0.005 from the best to the poorest combination tested. This weak sensitivity to the filter applied could be explained by both the weak surface variability of the frequencies considered and the barotropic character of this signal that was partially restored using the MOG2D model.

Conversely, some stations revealed significant variability. This was the case for instance with the Gadvos_2, Lampedusa_1, Ravenna, Taranto_1 and Viestre stations that showed an increased correlation of 0.02 to 0.06 for the 20-30 day filter with respect to

\section{Altimetric data in the Mediterranean Sea}

M.-I. Pujol et al.

\section{Title Page}

Abstract Introduction

Conclusions References

Tables Figures

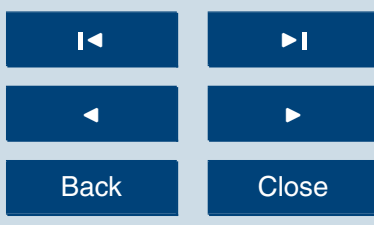

Full Screen / Esc

Printer-friendly Version

Interactive Discussion 
the 80-day one. This sensitivity seems to underline the importance of the signal with frequencies of between $30^{-1}$ and $80^{-1}$ days $^{-1}$, partially restored with the AOS, that cannot be entirely restored with the MOG2D model.

Very few stations showed better results when considering the 60 or 80-day filters.

5 This was the case with the Imperia, Palinuro_2 and Palinuro_4 stations. However, for these stations, the sensitivity to the filter remained very low since the variability of the correlation with tide gauge data did not exceed 0.02 from the 80-day to the 20-day filter.

Finally, the results obtained here showed that a relatively accurate estimate of the total surface signal could be obtained since the signal with intervals of greater than 30 1040 days, poorly restored with the AOS, could be completed using a barotropic model such as MOG2D. The different sensitivity tests showed that the best results were obtained by considering all the barotropic signals provided by the MOG2D model with the LF component of the altimetric signal. A mean 30-40 day low-pass filter seemed to give the best results. However, some considerable differences which were observed 15 between the total signal thus estimated and the tide gauge data, supposedly representative of the real total surface signal, implied that part of the signal was still missing in the combined signal. This was the case for instance with local coastal events that were not correctly observed or simulated because of the spatial/temporal resolution of the altimetric sampling or of the model and atmospheric forcing used. This was also the case with the non-barotropic HF surface variability that was not well restored by the AOS and was not part of the signal which was simulated with the model.

\subsection{Description of the total surface signal generated}

The results given above show that a relatively accurate estimate of the total surface signal can be obtained by combining the LF altimetric signal with the MOG2D 25 barotropic model outputs. In accordance with the previous results, we considered the AOS_MOG2D_LF30+MOG2D to be the best estimate of the total surface signal. The mean variability over the 11-year period [1993-2003] of this combined signal is given in Fig. 12a.

OSD

4, 571-622, 2007

\section{Altimetric data in the Mediterranean Sea}

M.-I. Pujol et al.

\section{Title Page}

Abstract Introduction

Conclusions References

Tables Figures

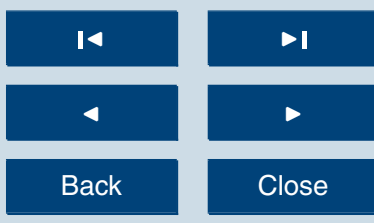

Full Screen / Esc

Printer-friendly Version

Interactive Discussion 
The mean variability of the total signal generated globally has the same characteristics as the variability of the altimetric signal over the [1993-1999] period represented by Larnicol et al. (2002).

The mean variance is nearly $90 \mathrm{~cm}^{2}$ over the whole sea, however it is generally 5 greater in the eastern basin. Some local variability extremes emphasise the annual to interannual variability of semi-permanent circulation structures (e.g., lerapetra Eddy, Alboran Gyres, Pelops and Bonifacio Gyres) or of some particular areas of intense mesoscale variability $\left(\Sigma A_{E}\right.$ and $\left.\Sigma L_{W}\right)$. In the western basin some patches of intense variability $\left(>80 \mathrm{~cm}^{2}\right)$ characterise the signature of sporadic energetic and long-lived 10 eddies (e.g., northern Balearic Sea and along the Algerian Current). In the Ionian Sea, the significant variability observed in the north/central part of the basin results from the major interannual variability of the circulation observed in this basin. The reader should refer to the paper of Larnicol et al. (2002) for a detailed description of these different signals.

15 However, unlike the variability discussed by Larnicol et al. (2002), the variability shown in Fig. 12 contains the contribution of the barotropic signal from the MOG2D model. As this component is LW signal, its mean contribution is a global increase in the mean signal variability of $\sim 12 \mathrm{~cm}^{2}$ with respect to the altimetric signal alone. The local contribution of this HF barotropic signal, locally significant, is better emphasised 20

by Fig. 12b. It represents the HF ( $>30^{-1}$ days $\left.^{-1}\right)$ barotropic signal's contribution to the variability of the total surface signal generated. This contribution is on average about $12 \%$ and it is particularly notable in the areas where a low variability in the altimetric signal was observed. Therefore, barotropic HF surface variability significantly adds to the variability of specific structures such as the Rhodes Gyre (nearly 16\%). The low variability of the altimetric signal observed along the Tyrrhenian coast and along the Liguro-Provençal current also contributes to the greater amount of variability explained by the HF barotropic signal in these areas. In fact, its contribution is nearly $19 \%$ along the Italian and French coasts. In the Gulf of Lions, the barotropic response to wind surface forcing leads to a local contribution to the HF signal of up to $20 \%$. Other areas

OSD

4, 571-622, 2007

\section{Altimetric data in the Mediterranean Sea}

M.-I. Pujol et al.

\section{Title Page}

Abstract Introduction

Conclusions References

Tables Figures

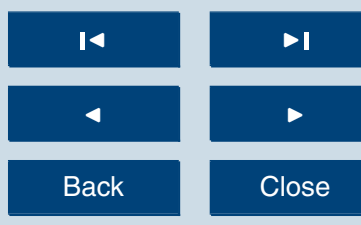

Full Screen / Esc

Printer-friendly Version

Interactive Discussion 
where barotropic variability is greater are also highlighted. This was the case with the Adriatic Sea where the HF variability accounts for up to $15 \%$ of the total signal variance. In the same way, south of the Ionian sea, the role of the circulation's HF barotropic response is quite clear since it accounts for nearly $16 \%$ of the variance along the Libyan 5 coast and up to $25 \%$ in the Gulf of Gabès. Conversely, the lowest contribution $(<7 \%)$ of the HF barotropic signal highlighted quite well the known circulation structures that vary considerably on an annual and interannual basis. This was the case with the different wind-induced gyres (IE, Pelops, Bonifacio, Alboran Gyres). The HF barotropic signal's contribution is also very low $(<10 \%)$ in areas with marked mesoscale variability (Alge10 rian Current and south of the Levantine basin). In the Ionian basin, where considerable interannual variability of the circulation was observed, the HF barotropic component's contribution was also relatively low $(<10 \%)$.

\section{Summary and conclusions}

The analysis of 11 years of altimetric SLA maps in the Mediterranean Sea revealed a 15 residual, spatially-correlated noise signal which altered the homogeneity of the maps. This study showed that this error signal resulted from a complex combination of alongtrack sampling and mapping of the surface signal, leading to both spatial and temporal aliasing of the HF LW variability.

An OSSE undertaken with 11 years of barotropic signals simulated by MOG2D clearly showed that the AOS was unable to restore the HF signal correctly, since frequencies higher than $40^{-1}-30^{-1}$ days ${ }^{-1}$ were largely underestimated with SLA maps.

Moreover, noise errors due to the aliasing effect of the HF LW signal were clearly identified when analysing the HF $\left(>30^{-1}\right.$ days $\left.^{-1}\right)$ signal ultimately restored. These errors highlighted the characteristics of the sampling of the HF LW signal by each satellite used.

One more significant error was revealed by the ERS/EN sampling. It was characterised by the presence of positive/negative vertically-structured bands with a thick-
OSD

4, 571-622, 2007

Altimetric data in the Mediterranean Sea

M.-I. Pujol et al.

\section{Title Page}

Abstract Introduction

Conclusions References

Tables Figures

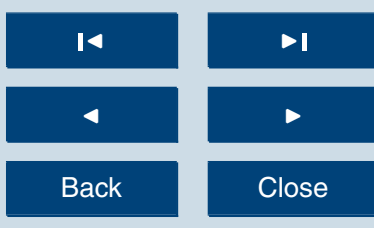

Full Screen / Esc

Printer-friendly Version

Interactive Discussion 
ness of nearly $600 \mathrm{~km}$ (for a couple of positive/negative bands). This signal error was identified by two different EOF modes accounting for respectively $3.4 \%$ and $2.8 \%$ of the HF $\left(>30^{-1}\right.$ days $\left.^{-1}\right)$ signal variance.

A second error clearly revealed the distribution of the TP/J1 tracks. The mode rep5 resentative of this error signal accounted for nearly $2.6 \%$ of the signal variance.

These aliasing errors can be further reduced by adjusting the empirical correction (Le Traon et al., 1998) which is applied. In fact, satisfactory results were obtained by more carefully considering the specific structure of the signal resulting from the alongtrack sampling of the HF LW signal. Considering the ERS/EN sampling, it was decided 10 to use a $600 \mathrm{~km}$ range correlation scale, instead of the $250 \mathrm{~km}$ range previously used.

However, empirical correction is unable to control precisely the signal corrected. Conversely, model-based corrections make better allowance for the physical process responsible for the HF LW surface variability. Such a MOG2D model-based correction, that consists in directly removing the HF LW signal simulated from along-track data,

fact, although the efficiency of such a correction had been previously demonstrated by Carrère et al. (2007) ${ }^{1}$ in the global ocean, and Mangiarotti and Lyard (2007) for the annual to interannual signal restitution, it did not seem to reduce the error signal linked to altimetric sampling of the HF LW signal in the Mediterranean Sea. While these results could be partially due to limitations of the MOG2D model (model resolution and accuracy/resolution of the forcing used), it also revealed the complex origin of the error signal observed. The results obtained seem to indicate that the HF LW non-barotropic signal, that is not included in the MOG2D output model but which represents a significant part of the signal at frequencies lower than $20^{-1}$ days $^{-1}$, largely contributes to the noise signal observed. Moreover, other corrections applied can contribute to this noise signal. This was the case, for example, with the inverse barometer contribution that was statically removed from the along-track signal, without taking into account the basin's delayed response to this forcing (Le Traon and Gauzelin, 1997).

Moreover, part of the noise signal, emphasising the distribution between TP/J1
OSD

4, 571-622, 2007

\section{Altimetric data in the Mediterranean Sea}

M.-I. Pujol et al.

\section{Title Page}

Abstract Introduction

Conclusions References

Tables Figures

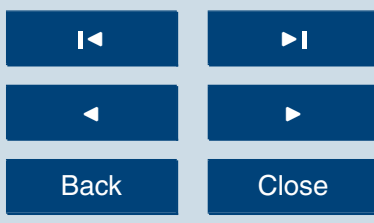

Full Screen / Esc

Printer-friendly Version

Interactive Discussion 
tracks, was still observed after applying either the empirical correction, or the MOG2D model-based correction. Studies undertaken over the period [2000-2005] where three to four satellites were available suggest that this signal resulted from a combination of satellite spatial coverage and capacity of the OA to propagate of LW information. 5 It could be reduced by increasing the satellite's spatial coverage and the number of altimeters whose data is merged.

Finally, it was demonstrated that a relatively accurate estimate of the total surface signal could be obtained by combining the correctly reconstructed LF signal with AOS maps with the barotropic signal simulated by the MOG2D model. Comparing the dif10 ferent combinations tested with the tide gauge signal showed considerable variability in the results, which can be explained by either the difficulty experienced by both the AOS and the MOG2D model in restoring local phenomenon, or the local importance of the non-barotropic HF surface signal that was not considered in the reconstructed total signal. Its accordance with the analysis of the AOS signal, applying a low-pass 30-40 15 day filter to the altimetry data before combining it with the MOG2D model contributed to an improved restitution of the total surface signal. Moreover, as previously observed by Lyard and Roblou (2003), the LF component of the MOG2D model, even with attenuated amplitude with respect to the real barotropic LF signal, also significantly improved the results.

20 The analysis of the total signal thus combined showed that the contribution of the barotropic HF component is significant on a localised basis. In fact it can account for between 10 and more than $25 \%$ of the total variance, especially in areas where low bathymetry and atmospheric forcing variability induce a strong HF barotropic response from the basin (Gulf of Lions, Adriatic Sea, Gulf of Gabès, Libyan coast) or in 25 areas where variability restored by the AOS appears very low (Tyrrhenian Sea, LiguroProvençal Current, Rhodes Gyre).

Acknowledgements. This paper is a tribute to all the members of the CLS team that produced the altimetry data. We are also grateful to the Italian agency APAT for providing tide gauge data and thank F. Lefèvre for his help in processing them.

OSD

4, 571-622, 2007

\section{Altimetric data in the Mediterranean Sea}

M.-I. Pujol et al.

Title Page

Abstract Introduction

Conclusions References

Tables Figures

I

14

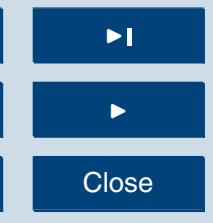

Full Screen / Esc

Printer-friendly Version

Interactive Discussion

EGU 


\section{References}

Carrère, L.: Etude et modelisation de la réponse haute fréquence de l'océan global aux forçages météorologiques, these de l'université Paul Sabatier Toulouse III, 2003.

Carrère, L. and Lyard, F.: Modeling the barotropic response of the global ocean to atmospheric $5 \quad$ wind and pressure forcing - comparison with observations, Geophys. Res. Lett., 30(6), 1275, doi:10.1029/2002GL016473, 2003.

Ducet, N., Le Traon, P.-Y., and Reverdun, G.: Global high-resolution mapping of the ocean circulation from TOPEX/Poseidon and ERS-1 and -2, J. Geophys. Res., 105(C8), 1947719 498, 2000.

10 ECMWF: European Centre for Medium-Range Forecasts Model, ECMWF research manual, 1991.

Fukumori, I., Raghunath, R., and Fu, L.-L.: Nature of large-scale sea level variability in relation to atmospheric forcing: A modeling study, J. Geophys. Res., 103(C3), 5493-5512, 1998.

Fukumori, I., Menemenlis, D., and Lee, T.: A Near-Uniform Basin Wide Sea Level Fluctuation of the Mediterranean Sea, J. Phys. Oceanogr., 37(2), 338-358, 2007.

Larnicol, G., Ayoub, N., and Le Traon, P.-Y.: Major changes in the Mediterranean Sea level variabilità from 7 years of Topex/Poseidon and ERS-1/2 data., J. Mar. Syst., 33-34, 63-89, 2002.

Le Traon, P.-Y. and Gauzelin, P.: Response of the Mediterranean mean sea level to atmospheric pressure forcing, J. Geophys. Res., 102(C1), 973-984, 1997.

Le Traon, P.-Y. and Ogor, F.: ERS-1/2 orbit improvement using TOPEX/POSEIDON: the $2 \mathrm{~cm}$ challenge, J. Geophys. Res., 103, 8045-8057, 1998.

Le Traon, P.-Y., Nadal, F., and Ducet, N.: An improved mapping method of multisatellite altimeter data, J. Atmos. Oceanic Technol., 15, 522-534, 1998.

Lyard, F. and Roblou, L.: Prévision de produit combine du niveau de la mer en Méditerranée - comparaisons avec des observations, La letter trimestrielle de MERCATOR, 10, 17-27, 2003.

Mangiarotti, S. and Lyard, F.: Surface Pressure and Wind Stress Effect on Sea Level Change Estimations From TOPEX-POSEIDON Satellite Altimetry in the Mediterranean Sea, J. At-

Pujol, M.-I. and Larnicol, G.: Mediterranean Sea eddy kinetic energy variability from 11 years of altimetric data, J. Mar. Syst., 58, 121-142, 2005.

OSD

4, 571-622, 2007

Altimetric data in the Mediterranean Sea

M.-I. Pujol et al.

\section{Title Page}

Abstract Introduction

Conclusions

References

Tables

Figures

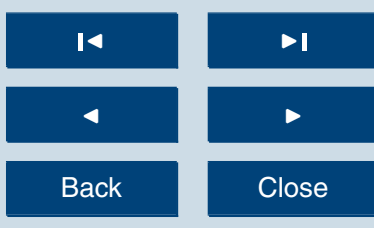

Full Screen / Esc

Printer-friendly Version

Interactive Discussion 
Table 1. Characteristics of the tide gauge stations used.

\begin{tabular}{|c|c|c|c|}
\hline Station & Latitude $\left({ }^{\circ} \mathrm{N}\right)$ & Longitude $\left({ }^{\circ} \mathrm{E}\right)$ & Period considered \\
\hline Ancona & 43.629 & 13.504 & [5 Jan 1993-28 Sep 2004] \\
\hline Carloforte & 39.143 & 8.308 & [26 May 1999-28 Sep 2004] \\
\hline Catania_1 & 37.497 & 15.0934 & [5 Jan 1993-31 Aug 1997] \\
\hline Catania_2 & 37.497 & 15.0934 & [27 July 1998-28 Sep 2004] \\
\hline Civitavecchia & 39.078 & 13.116 & [4 Nov 1998-28 Sep 2004] \\
\hline Crotone_1 & 39.023 & 17.220 & [18 April 1995-22 June 1998] \\
\hline Crotone_2 & 39.023 & 17.220 & [31 Dec 1999-28 Sep 2004] \\
\hline Gavdos_1 & 34.848 & 24.119 & [30 Sep 2002-3 Nov 2003] \\
\hline Gavdos_2 & 34.848 & 24.119 & [19 Nov 2003-10 Aug 2004] \\
\hline Genova & 44.409 & 8.926 & [14 Sep 1998-30 Dec 2001] \\
\hline Hadera & 32.4705 & 34.8631 & [5 Feb 2003-2 Oct 2004] \\
\hline Imperia & 43.877 & 8.019 & [2 July 1998-28 Sep 2004] \\
\hline Lampedusa_1 & 35.483 & 12.617 & [31 Dec 1999-30 Dec 2001] \\
\hline Lampedusa_2 & 35.483 & 12.617 & [1 Jan 2004-28 Sep 2004] \\
\hline Livorno & 43.545 & 10.300 & [1 July 1998-28 Sep 2004] \\
\hline Messina_1 & 38.189 & 15.565 & [5 Jan 2001-29 Dec 2001] \\
\hline Messina_2 & 38.189 & 15.565 & [1 Jan 2002-28 Sep 2004] \\
\hline Napoli_1 & 40.840 & 14.269 & [1 Oct 1995-24 Dec 1997] \\
\hline Napoli_2 & 40.840 & 14.269 & [20 June 1998-28 Sep 2004] \\
\hline Ortona_1 & 42.356 & 14.416 & [5 Jan 1993-29 May 1994] \\
\hline Ortona_2 & 42.356 & 14.416 & [2 July 1999-30 Dec 2001] \\
\hline Otranto_1 & 40.146 & 18.497 & [31 Dec 1992-22 June 1998] \\
\hline Otranto_2 & 40.146 & 18.497 & [3 July 1998-2 Oct 2004] \\
\hline Palinuro_1 & 40.031 & 15.275 & [4 Jan 1995-16 Dec 1997] \\
\hline Palinuro_2 & 40.031 & 15.275 & [1 Jan 2001-28 Dec 2001] \\
\hline Palinuro_3 & 40.031 & 15.275 & [2 Jan 2002-13 Nov 2002] \\
\hline Palinuro_4 & 40.031 & 15.275 & [19 Jan 2003-28 Sep 2004] \\
\hline Porto Empedocle & 37.290 & 13.524 & [15 Sep 1998-28 Sep 2004] \\
\hline Portomaso & 35.909 & 14.519 & [30 Sep 2002-2 Oct 2004] \\
\hline Portotorres & 40.841 & 8.404 & [31 Dec 1999-28 Sep 2004] \\
\hline Ravenna & 44.497 & 12.280 & [24 Feb 1999-28 Sep 2004] \\
\hline Reggio Calabria & 38.121 & 15.649 & [23 April 1999-28 Sep 2004] \\
\hline Salerno_1 & 40.681 & 14.748 & [19 Sep 1995-25 Oct 1997] \\
\hline Salerno_2 & 40.681 & 14.748 & [29 July 1999-28 Sep 2004] \\
\hline Taranto_1 & 40.475 & 17.225 & [5 Jan 1993-10 May 1994] \\
\hline Taranto_2 & 40.475 & 17.225 & [12 Jan 1995-21 Oct 1997] \\
\hline Taranto_3 & 40.475 & 17.225 & [29 Dec 1998-28 Sep 2004] \\
\hline Valencia & 39.460 & 39.460 & [31 Dec 2003-2 Oct 2004] \\
\hline Vieste & 41.892 & 16.175 & [28 Aug 1998-7 Jan 2004] \\
\hline
\end{tabular}

Altimetric data in the Mediterranean Sea

M.-I. Pujol et al.

Title Page

Abstract

Introduction

Conclusions

References

Tables

Figures

I

14

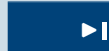

4

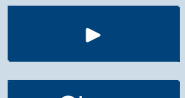

Back

Close

Full Screen / Esc

Printer-friendly Version

Interactive Discussion 
Table 2. Results from the comparison of the AOS_MOG2D_LF30+MOG2D, AOS_MOG2D_LF30+MOG2D_HF30, AOS_600_LF30+MOG2D and AOS_250_LF30+MOG2D signals with tide gauge signals. Both combined and tide gauge signals were low-pass filtered $\left(20^{-1}\right.$ days $^{-1}$ cut-frequency) before comparison. Three types of results are given: 1$)$ std = standard deviation of the difference between the two signals. 2) \% = extent of the variability of the misfit signal expressed as a percentage of the tide gauge signal. 3) corr = correlation between the combined and tide gauge signals.

\begin{tabular}{|c|c|c|c|c|c|c|c|c|c|}
\hline & \multicolumn{3}{|c|}{ AOS_MOG2D_LF30 + MOG2D } & \multicolumn{3}{|c|}{ AOS_600_LF30 + MOG2D } & \multicolumn{3}{|c|}{ AOS_250_LF30 + MOG2D } \\
\hline & std & $\%$ var & corr & std & $\%$ var & corr & std & $\%$ var & corr \\
\hline Ancona & 4.01 & 24.22 & 0.87 & 4.05 & 24.71 & 0.87 & 3.96 & 23.63 & 0.88 \\
\hline Carloforte & 3.65 & 41.21 & 0.80 & 3.38 & 35.51 & 0.83 & 3.59 & 40.03 & 0.81 \\
\hline Catania_1 & 3.39 & 34.85 & 0.91 & 3.32 & 33.33 & 0.89 & 3.48 & 36.67 & 0.90 \\
\hline Catania_2 & 2.58 & 19.50 & 0.91 & 2.04 & 12.24 & 0.95 & 2.29 & 15.33 & 0.92 \\
\hline Civitavecchia & 5.02 & 78.20 & 0.67 & 5.02 & 78.25 & 0.67 & 5.14 & 81.99 & 0.65 \\
\hline Crotone_1 & 3.08 & 25.84 & 0.93 & 3.07 & 25.74 & 0.94 & 3.60 & 35.29 & 0.91 \\
\hline Crotone_2 & 2.14 & 13.22 & 0.94 & 2.27 & 14.83 & 0.94 & 2.04 & 12.04 & 0.95 \\
\hline Gavdos_1 & 3.38 & 26.22 & 0.97 & 3.08 & 21.85 & 0.99 & 3.42 & 26.80 & 0.98 \\
\hline Gavdos_2 & 2.37 & 32.31 & 0.97 & 1.06 & 6.51 & 0.99 & 1.60 & 14.82 & 0.98 \\
\hline Genova & 2.12 & 15.09 & 0.93 & 2.34 & 18.34 & 0.92 & 2.34 & 18.44 & 0.90 \\
\hline Hadera & 2.59 & 26.98 & 0.94 & 3.02 & 36.66 & 0.93 & 3.39 & 46.07 & 0.91 \\
\hline Imperia & 1.62 & 9.32 & 0.96 & 2.36 & 19.72 & 0.92 & 2.51 & 22.19 & 0.90 \\
\hline Lampedusa_1 & 1.67 & 7.23 & 0.97 & 1.57 & 6.40 & 0.97 & 1.53 & 6.08 & 0.97 \\
\hline Lampedusa_2 & 1.64 & 11.98 & 0.97 & 1.38 & 8.51 & 0.97 & 1.34 & 7.99 & 0.97 \\
\hline $\begin{array}{l}\text { Livorno } \\
\end{array}$ & 2.43 & 21.23 & 0.91 & 2.94 & 31.21 & 0.87 & 3.17 & 36.30 & 0.84 \\
\hline Messina_1 & 2.83 & 30.67 & 0.89 & 3.01 & 34.64 & 0.86 & 2.92 & 32.61 & 0.85 \\
\hline Messina_2 & 2.65 & 24.00 & 0.89 & 2.98 & 30.37 & 0.88 & 2.93 & 29.29 & 0.85 \\
\hline Napoli_1 & 2.08 & 12.65 & 0.96 & 2.44 & 17.44 & 0.96 & 2.16 & 13.66 & 0.94 \\
\hline Napoli_2 & 3.33 & 40.06 & 0.82 & 2.98 & 32.05 & 0.85 & 2.96 & 31.73 & 0.84 \\
\hline Ortona_1 & 3.88 & 26.95 & 0.88 & 4.41 & 34.79 & 0.83 & 4.84 & 41.84 & 0.78 \\
\hline Ortona_2 & 2.94 & 20.56 & 0.89 & 2.25 & 12.08 & 0.95 & 2.37 & 13.30 & 0.94 \\
\hline Otranto_1 & 4.31 & 29.33 & 0.84 & 4.86 & 37.24 & 0.80 & 4.51 & 32.06 & 0.83 \\
\hline Otranto_2 & 4.54 & 53.78 & 0.69 & 3.91 & 39.91 & 0.78 & 4.14 & 44.65 & 0.75 \\
\hline Palinuro_1 & 2.40 & 15.55 & 0.93 & 2.48 & 16.66 & 0.93 & 2.64 & 18.87 & 0.91 \\
\hline Palinuro_2 & 2.65 & 24.92 & 0.92 & 1.78 & 11.31 & 0.94 & 1.90 & 12.92 & 0.94 \\
\hline Palinuro_3 & 1.82 & 12.72 & 0.94 & 2.41 & 22.42 & 0.90 & 2.53 & 24.69 & 0.89 \\
\hline Palinuro_4 & 2.05 & 20.75 & 0.93 & 2.17 & 23.21 & 0.93 & 1.62 & 12.88 & 0.95 \\
\hline Porto Empedocle & 2.40 & 20.42 & 0.91 & 1.98 & 13.82 & 0.94 & 2.10 & 15.65 & 0.92 \\
\hline Portomaso & 2.87 & 14.07 & 0.97 & 2.61 & 11.65 & 0.97 & 2.74 & 12.80 & 0.96 \\
\hline Portotorres & 2.74 & 25.65 & 0.87 & 2.67 & 24.42 & 0.89 & 2.65 & 24.12 & 0.90 \\
\hline Ravenna & 3.38 & 25.00 & 0.91 & 2.79 & 17.08 & 0.91 & 3.50 & 26.84 & 0.89 \\
\hline Reggio Calabria & 2.24 & 14.36 & 0.93 & 2.11 & 12.76 & 0.94 & 2.29 & 15.00 & 0.92 \\
\hline Salerno_1 & 2.08 & 15.66 & 0.94 & 2.61 & 24.66 & 0.93 & 2.09 & 15.72 & 0.93 \\
\hline Salerno_2 & 5.39 & 67.35 & 0.61 & 4.94 & 56.70 & 0.68 & 4.80 & 53.55 & 0.69 \\
\hline Taranto_1 & 2.08 & 15.11 & 0.95 & 2.72 & 25.79 & 0.93 & 2.27 & 17.99 & 0.93 \\
\hline Taranto_2 & 2.45 & 15.13 & 0.93 & 2.68 & 18.01 & 0.93 & 2.72 & 18.56 & 0.92 \\
\hline Taranto_3 3 & 2.41 & 16.53 & 0.92 & 2.26 & 14.50 & 0.93 & 2.33 & 15.43 & 0.92 \\
\hline Valencia & 2.49 & 44.28 & 0.90 & 2.06 & 30.53 & 0.93 & 3.18 & 72.47 & 0.88 \\
\hline Vieste & 2.77 & 25.20 & 0.89 & 3.07 & 30.84 & 0.88 & 3.06 & 30.67 & 0.88 \\
\hline MEAN & 2.84 & 25.66 & 0.90 & 2.81 & 24.88 & 0.90 & 2.90 & 27.03 & 0.89 \\
\hline
\end{tabular}

OSD

4, 571-622, 2007

Altimetric data in the Mediterranean Sea

M.-I. Pujol et al.

\section{Title Page}

\section{Abstract}

Introduction

Conclusions

References

Tables

Figures

14
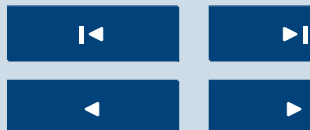

4

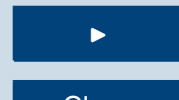

Back

Close

Full Screen / Esc

Printer-friendly Version

Interactive Discussion 
Table 3. Results from the comparison of the AOS_MOG2D_LF30+MOG2D and AOS_MOG2D_LF30+MOG2D_HF30 signals with tide gauge data. Three types of results are given: 1) std = standard deviation of the difference between the two signals. 2) $\%=$ extent of the variability of the misfit signal expressed as a percentage of the tide gauge signal. 3) corr = correlation between the combined and tide gauge signals.

\begin{tabular}{|c|c|c|c|c|c|c|}
\hline & \multicolumn{3}{|c|}{ AOS_MOG2D_LF30 + MOG2D } & \multicolumn{3}{|c|}{ AOS_MOG2D_LF30 + MOG2D_HF30 } \\
\hline & std & $\%$ var & corr & std & $\%$ var & corr \\
\hline Ancona & 6.30 & 39.30 & 0.80 & 6.63 & 43.54 & 0.76 \\
\hline Carloforte & 4.94 & 48.16 & 0.75 & 4.80 & 45.57 & 0.75 \\
\hline Catania_1 & 4.52 & 38.47 & 0.86 & 4.48 & 37.87 & 0.83 \\
\hline Catania_2 & 4.13 & 31.95 & 0.85 & 4.25 & 33.72 & 0.83 \\
\hline Civitavecchia & 6.21 & 74.78 & 0.65 & 6.46 & 81.14 & 0.60 \\
\hline Crotone_1 & 4.42 & 32.72 & 0.87 & 4.21 & 29.78 & 0.85 \\
\hline Crotone_2 & 3.79 & 25.69 & 0.88 & 3.84 & 26.38 & 0.86 \\
\hline Gavdos_1 & 4.52 & 32.47 & 0.92 & 3.78 & 22.81 & 0.92 \\
\hline Gavdos_2 & 4.19 & 36.89 & 0.85 & 4.22 & 37.56 & 0.81 \\
\hline Genova & 3.90 & 32.37 & 0.84 & 4.14 & 36.47 & 0.81 \\
\hline Hadera & 4.04 & 32.06 & 0.87 & 4.67 & 42.86 & 0.79 \\
\hline Imperia & 3.46 & 27.90 & 0.87 & 3.41 & 27.01 & 0.86 \\
\hline Lampedusa_1 & 3.21 & 17.37 & 0.92 & 3.05 & 15.77 & 0.92 \\
\hline Lampedusa_2 & 3.57 & 25.51 & 0.89 & 3.54 & 25.03 & 0.87 \\
\hline $\begin{array}{l}\text { Livorno } \\
\text { Len }\end{array}$ & 4.08 & 36.45 & 0.83 & 4.38 & 42.01 & 0.79 \\
\hline Messina_1 & 4.30 & 47.57 & 0.81 & 4.45 & 50.78 & 0.77 \\
\hline Messina_2 & 3.67 & 29.22 & 0.86 & 3.92 & 33.37 & 0.82 \\
\hline Napoli_1 & 3.77 & 26.59 & 0.88 & 3.88 & 28.10 & 0.85 \\
\hline Napoli_2 & 4.54 & 48.11 & 0.78 & 4.55 & 48.30 & 0.76 \\
\hline Ortona_1 & 5.60 & 35.06 & 0.81 & 6.19 & 42.81 & 0.76 \\
\hline Ortona_2 & 5.00 & 33.67 & 0.82 & 5.16 & 35.89 & 0.80 \\
\hline Otranto_1 & 6.74 & 43.94 & 0.75 & 6.77 & 44.34 & 0.75 \\
\hline Otranto_2 & 5.44 & 48.65 & 0.73 & 5.49 & 49.45 & 0.71 \\
\hline Palinuro_1 & 3.83 & 27.90 & 0.87 & 3.92 & 29.18 & 0.85 \\
\hline Palinuro_2 & 4.45 & 40.61 & 0.83 & 4.76 & 46.61 & 0.78 \\
\hline Palinuro_3 & 3.24 & 29.92 & 0.85 & 3.48 & 34.36 & 0.82 \\
\hline Palinuro_4 & 3.85 & 40.98 & 0.83 & 3.81 & 40.26 & 0.81 \\
\hline Porto Empedocle & 4.30 & 37.12 & 0.82 & 4.38 & 38.56 & 0.79 \\
\hline Portomaso & 4.73 & 25.73 & 0.90 & 4.56 & 23.95 & 0.89 \\
\hline Portotorres & 4.41 & 42.90 & 0.79 & 4.29 & 40.55 & 0.79 \\
\hline Ravenna & 6.48 & 50.04 & 0.79 & 6.49 & 50.24 & 0.75 \\
\hline Reggio Calabria & 3.87 & 27.63 & 0.87 & 3.94 & 28.53 & 0.85 \\
\hline Salerno_1 & 4.00 & 33.63 & 0.84 & 4.07 & 34.76 & 0.81 \\
\hline Salerno_2 & 6.30 & 65.64 & 0.63 & 5.98 & 59.07 & 0.65 \\
\hline Taranto_1 & 4.90 & 34.80 & 0.82 & 5.36 & 41.65 & 0.77 \\
\hline Taranto_2 & 3.81 & 24.78 & 0.88 & 3.85 & 25.33 & 0.86 \\
\hline Taranto_3 & 3.86 & 26.30 & 0.86 & 3.84 & 26.03 & 0.86 \\
\hline Valencia & 4.00 & 46.83 & 0.80 & 4.25 & 52.86 & 0.77 \\
\hline Vieste & 4.38 & 33.49 & 0.83 & 4.31 & 32.49 & 0.82 \\
\hline MEAN & 4.48 & 36.75 & 0.83 & 4.59 & 38.31 & 0.80 \\
\hline
\end{tabular}

OSD

4, 571-622, 2007

Altimetric data in the Mediterranean Sea

M.-I. Pujol et al.

Title Page

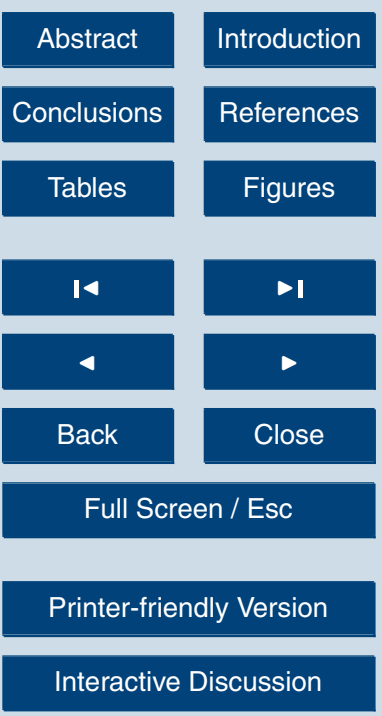

EGU 
Table 4. Results from the comparison of the combined signal considering total MOG2D output and AOS_MOG2D low-pass filtered with a different cut-frequency. Two types of results are given: 1) std = standard deviation of the difference between the two signals. 2) corr = correlation between the combined and tide gauge signals.

\begin{tabular}{|c|c|c|c|c|c|c|c|c|c|c|}
\hline & \multicolumn{2}{|c|}{$\begin{array}{c}\text { AOS_MOG2D_LF20 } \\
+ \text { MOG2D }\end{array}$} & \multicolumn{2}{|c|}{$\begin{array}{c}\text { AOS_MOG2D_LF30 } \\
+ \text { MOG2D }\end{array}$} & \multicolumn{2}{|c|}{$\begin{array}{c}\text { AOS_MOG2D_LF40 } \\
+ \text { MOG2D }\end{array}$} & \multicolumn{2}{|c|}{$\begin{array}{c}\text { AOS_MOG2D_LF60 } \\
+ \text { MOG2D }\end{array}$} & \multicolumn{2}{|c|}{$\begin{array}{c}\text { AOS_MOG2D_LF80 } \\
+ \text { MOG2D }\end{array}$} \\
\hline & std & corr & std & corr & std & corr & std & corr & std & corr \\
\hline Ancona & 6.30 & 0.80 & 6.30 & 0.80 & 6.35 & 0.79 & 6.45 & 0.78 & 6.49 & 0.77 \\
\hline Carloforte & 4.98 & 0.75 & 4.94 & 0.75 & 4.87 & 0.76 & 4.84 & 0.76 & 4.84 & 0.75 \\
\hline Catania_1 & 4.58 & 0.86 & 4.52 & 0.86 & 4.44 & 0.86 & 4.49 & 0.85 & 4.53 & 0.84 \\
\hline Catania_2 & 4.24 & 0.85 & 4.13 & 0.85 & 4.00 & 0.85 & 4.01 & 0.85 & 4.02 & 0.85 \\
\hline Civitavecchia & 6.21 & 0.65 & 6.21 & 0.65 & 6.20 & 0.65 & 6.19 & 0.64 & 6.19 & 0.64 \\
\hline Crotone_1 & 4.43 & 0.87 & 4.42 & 0.87 & 4.42 & 0.86 & 4.50 & 0.85 & 4.53 & 0.85 \\
\hline Crotone_2 & 3.82 & 0.88 & 3.79 & 0.88 & 3.76 & 0.88 & 3.78 & 0.87 & 3.80 & 0.87 \\
\hline Gavdos_1 & 4.54 & 0.92 & 4.52 & 0.92 & 4.54 & 0.91 & 4.61 & 0.90 & 4.60 & 0.90 \\
\hline Gavdos_2 & 4.16 & 0.86 & 4.19 & 0.85 & 4.30 & 0.84 & 4.39 & 0.82 & 4.42 & 0.81 \\
\hline Genova & 3.93 & 0.83 & 3.90 & 0.84 & 3.87 & 0.83 & 3.88 & 0.83 & 3.90 & 0.83 \\
\hline Hadera & 4.04 & 0.87 & 4.04 & 0.87 & 4.03 & 0.86 & 3.99 & 0.86 & 4.01 & 0.85 \\
\hline Imperia & 3.52 & 0.86 & 3.46 & 0.87 & 3.37 & 0.87 & 3.33 & 0.87 & 3.35 & 0.87 \\
\hline Lampedusa_1 & 3.16 & 0.92 & 3.21 & 0.92 & 3.40 & 0.90 & 3.60 & 0.89 & 3.68 & 0.88 \\
\hline Lampedusa_2 & 3.60 & 0.89 & 3.57 & 0.89 & 3.55 & 0.88 & 3.58 & 0.87 & 3.65 & 0.86 \\
\hline Livorno & 4.13 & 0.83 & 4.08 & 0.83 & 4.01 & 0.83 & 3.99 & 0.83 & 3.99 & 0.83 \\
\hline Messina_1 & 4.34 & 0.81 & 4.30 & 0.81 & 4.23 & 0.81 & 4.19 & 0.80 & 4.21 & 0.79 \\
\hline Messina_2 & 3.70 & 0.86 & 3.67 & 0.86 & 3.68 & 0.86 & 3.71 & 0.85 & 3.68 & 0.85 \\
\hline Napoli_1 & 3.82 & 0.88 & 3.77 & 0.88 & 3.75 & 0.88 & 3.80 & 0.87 & 3.86 & 0.87 \\
\hline Napoli_2 & 4.59 & 0.78 & 4.54 & 0.78 & 4.47 & 0.78 & 4.42 & 0.78 & 4.41 & 0.78 \\
\hline Ortona_1 & 5.57 & 0.81 & 5.60 & 0.81 & 5.72 & 0.80 & 5.81 & 0.79 & 5.81 & 0.79 \\
\hline Ortona_2 & 5.01 & 0.82 & 5.00 & 0.82 & 5.01 & 0.82 & 5.06 & 0.81 & 5.11 & 0.81 \\
\hline Otranto_1 & 6.74 & 0.75 & 6.74 & 0.75 & 6.75 & 0.75 & 6.77 & 0.75 & 6.77 & 0.75 \\
\hline Otranto_2 & 5.44 & 0.73 & 5.44 & 0.73 & 5.45 & 0.72 & 5.47 & 0.72 & 5.49 & 0.71 \\
\hline Palinuro_1 & 3.90 & 0.87 & 3.83 & 0.87 & 3.72 & 0.88 & 3.69 & 0.87 & 3.72 & 0.87 \\
\hline Palinuro_2 & 4.54 & 0.83 & 4.45 & 0.83 & 4.25 & 0.84 & 4.07 & 0.84 & 4.06 & 0.84 \\
\hline Palinuro_3 & 3.24 & 0.85 & 3.24 & 0.85 & 3.31 & 0.84 & 3.38 & 0.83 & 3.38 & 0.83 \\
\hline Palinuro_4 & 3.87 & 0.83 & 3.85 & 0.83 & 3.73 & 0.83 & 3.52 & 0.85 & 3.41 & 0.85 \\
\hline Porto Empedocle & 4.32 & 0.82 & 4.30 & 0.82 & 4.27 & 0.81 & 4.27 & 0.81 & 4.29 & 0.81 \\
\hline Portomaso & 4.77 & 0.90 & 4.73 & 0.90 & 4.69 & 0.90 & 4.72 & 0.89 & 4.77 & 0.89 \\
\hline Portotorres & 4.50 & 0.79 & 4.41 & 0.79 & 4.23 & 0.80 & 4.11 & 0.81 & 4.10 & 0.80 \\
\hline Ravenna & 6.51 & 0.79 & 6.48 & 0.79 & 6.44 & 0.78 & 6.44 & 0.77 & 6.47 & 0.77 \\
\hline Reggio Calabria & 3.92 & 0.86 & 3.87 & 0.87 & 3.83 & 0.87 & 3.82 & 0.86 & 3.82 & 0.86 \\
\hline Salerno_1 & 4.03 & 0.84 & 4.00 & 0.84 & 3.94 & 0.84 & 3.91 & 0.84 & 3.94 & 0.84 \\
\hline Salerno_2 & 6.32 & 0.63 & 6.30 & 0.63 & 6.28 & 0.63 & 6.29 & 0.62 & 6.31 & 0.62 \\
\hline Taranto_1 & 4.85 & 0.83 & 4.90 & 0.82 & 5.07 & 0.80 & 5.33 & 0.78 & 5.43 & 0.77 \\
\hline Taranto_2 & 3.85 & 0.88 & 3.81 & 0.88 & 3.81 & 0.88 & 3.93 & 0.86 & 4.02 & 0.86 \\
\hline Taranto_3 & 3.87 & 0.86 & 3.86 & 0.86 & 3.87 & 0.86 & 3.93 & 0.85 & 3.97 & 0.85 \\
\hline Valencia & 4.02 & 0.80 & 4.00 & 0.80 & 3.97 & 0.80 & 3.96 & 0.80 & 3.96 & 0.80 \\
\hline Vieste & 4.34 & 0.84 & 4.38 & 0.83 & 4.50 & 0.82 & 4.61 & 0.81 & 4.64 & 0.80 \\
\hline MEAN & 4.54 & 0.83 & 4.52 & 0.83 & 4.50 & 0.82 & 4.52 & 0.82 & 4.54 & 0.81 \\
\hline
\end{tabular}

OSD

$4,571-622,2007$

Altimetric data in the Mediterranean Sea

M.-I. Pujol et al.

Title Page

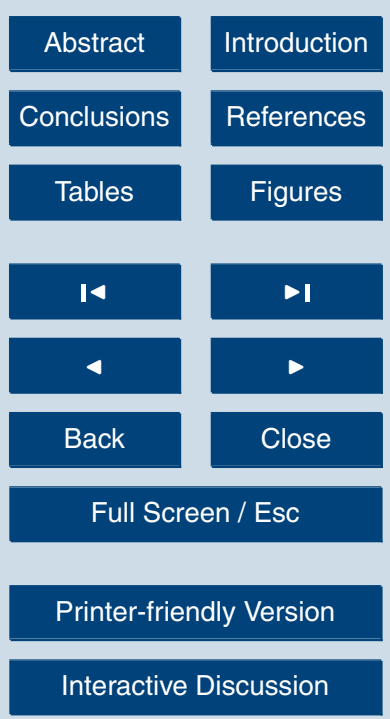

EGU 
OSD

4, 571-622, 2007

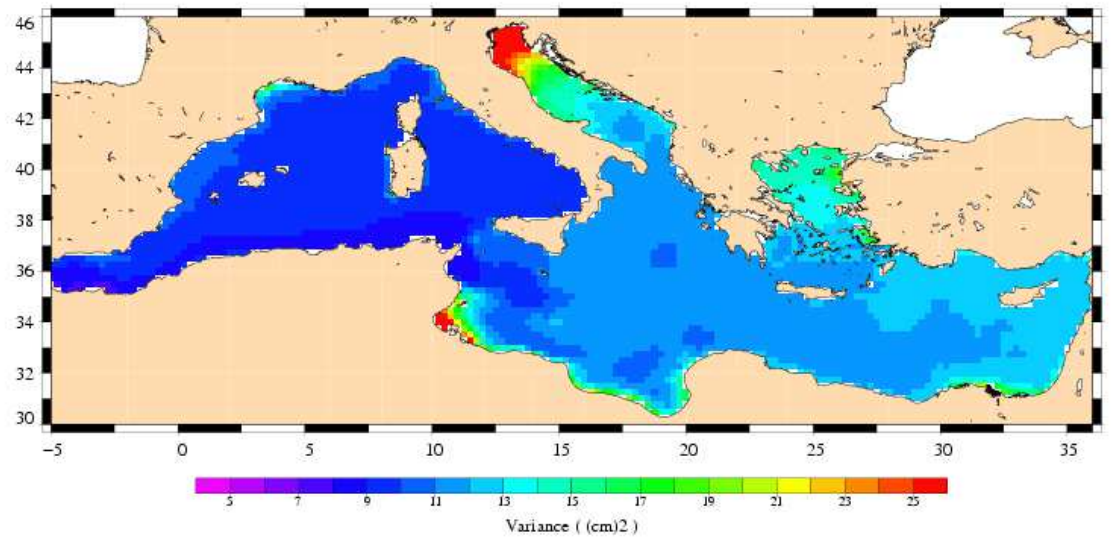

Fig. 1. Variance of the HF $\left(>30^{-1}\right.$ days $\left.^{-1}\right)$ barotropic signal simulated by the MOG2D model over the 11-year period [1993-2003].

\section{Altimetric data in the Mediterranean Sea}

M.-I. Pujol et al.

\begin{tabular}{|c|c|}
\hline \multicolumn{2}{|c|}{ Title Page } \\
\hline Abstract & Introduction \\
\hline Conclusions & References \\
\hline Tables & Figures \\
\hline Iu & $\bullet$ \\
\hline $\mathbf{1}$ & $\bullet$ \\
\hline Back & Close \\
\hline Full Screen / Esc
\end{tabular}

Printer-friendly Version

Interactive Discussion 

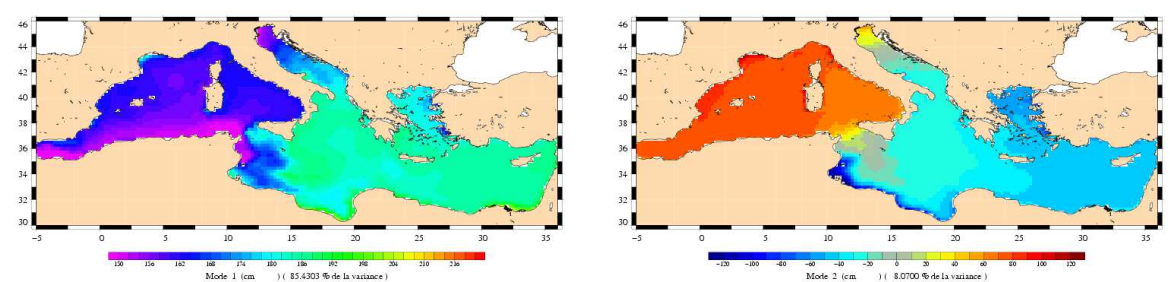

(a)

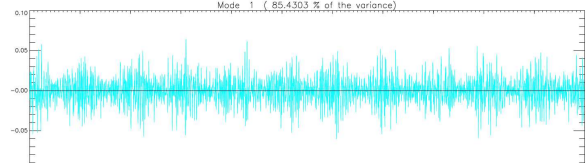

(b)

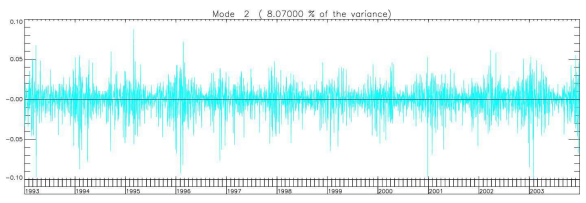

Fig. 2. EOF decomposition of the HF $\left(>30^{-1}\right.$ days $\left.^{-1}\right)$ barotropic signal simulated by the MOG2D model. Spatial and temporal characteristic of the first (a) and second (b) modes.
Altimetric data in the Mediterranean Sea

M.-I. Pujol et al.

Title Page

Abstract

Introduction

Conclusions

References

Tables

Figures

14

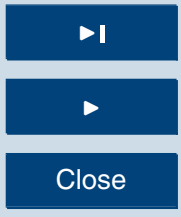

Full Screen / Esc

Printer-friendly Version

Interactive Discussion 


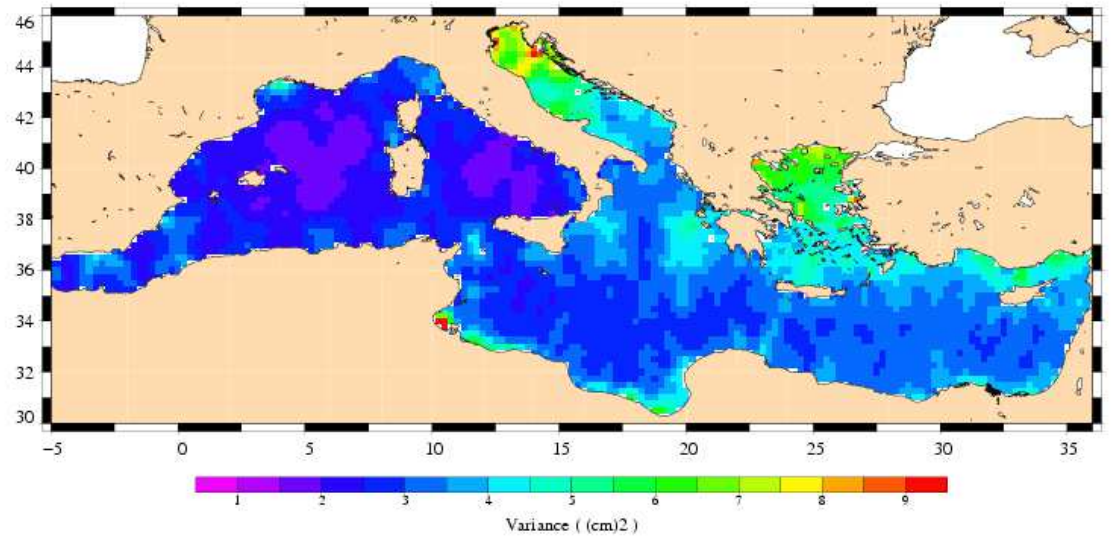

Fig. 3. Variance of the OSSE_250 signal (MOG2D signal sampled by altimetric measurement and mapped using the $250 \mathrm{~km}$ parameterisation for empirical correction of inter-track bias) over the 11-year period [1993-2003].

\section{Altimetric data in the Mediterranean Sea}

M.-I. Pujol et al.

Title Page

\section{Abstract}

Introduction

Conclusions

References

Tables

Figures

14

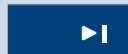

4

Back

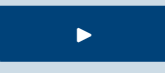

Close

Full Screen / Esc

Printer-friendly Version

Interactive Discussion 


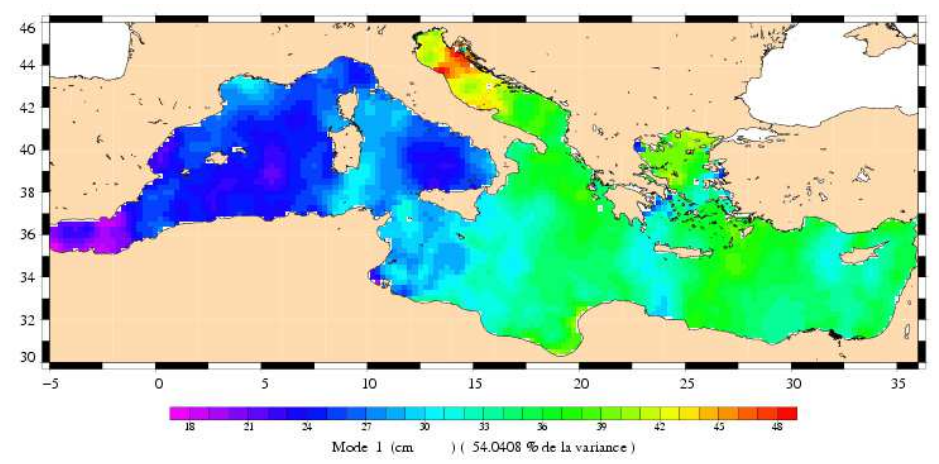

(a)

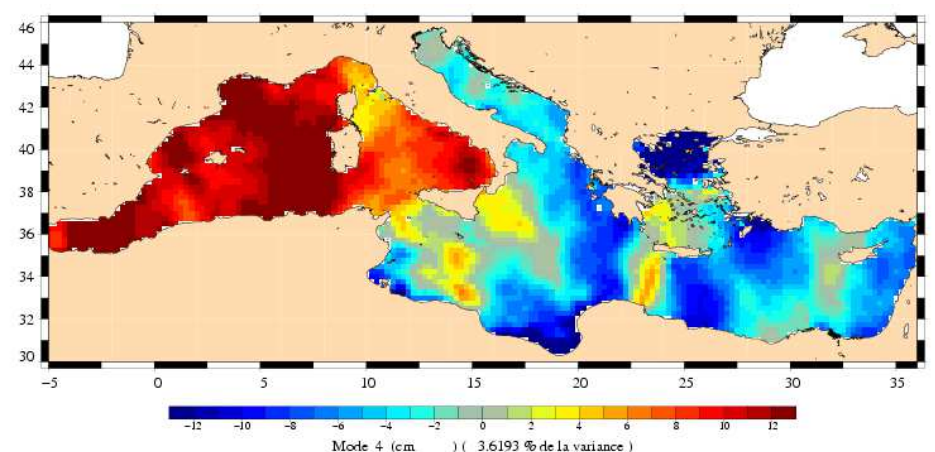

(b)

Fig. 4. EOF decomposition of the OSSE_250 signal. Spatial component for (a) first mode, (b) fourth mode.
OSD

4, 571-622, 2007

Altimetric data in the Mediterranean Sea

M.-I. Pujol et al.

Title Page

\section{Abstract}

Introduction

Conclusions

References

Tables

Figures

14

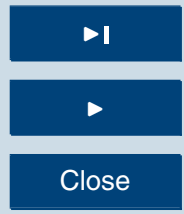

Back

Full Screen / Esc

Printer-friendly Version

Interactive Discussion 


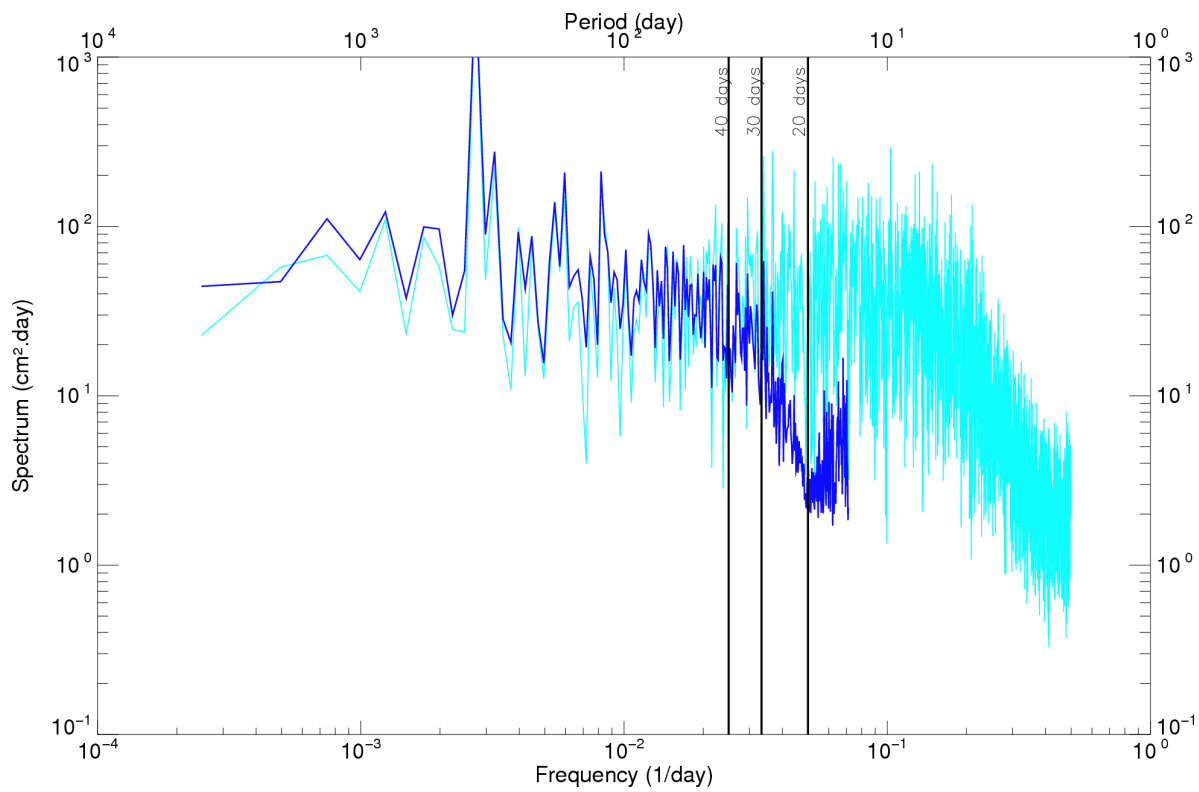

Fig. 5. Power/frequency spectrum of the MOG2D signal (light blue line) and of this signal restored after altimetric sampling and mapping (OSSE_600 signal) (dark blue line).
Altimetric data in the Mediterranean Sea

M.-I. Pujol et al.

Title Page

\section{Abstract}

Introduction

Conclusions

References

Tables

Figures

14

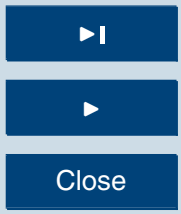

Back

Full Screen / Esc

Printer-friendly Version

Interactive Discussion 


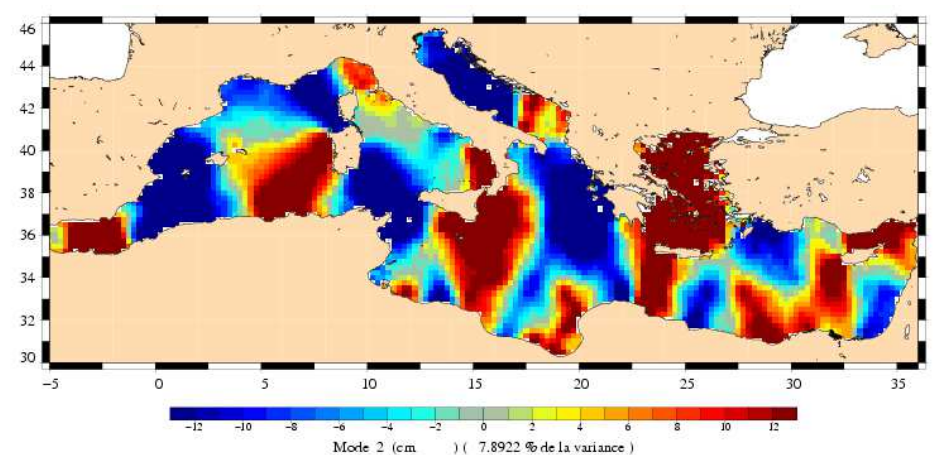

(a)

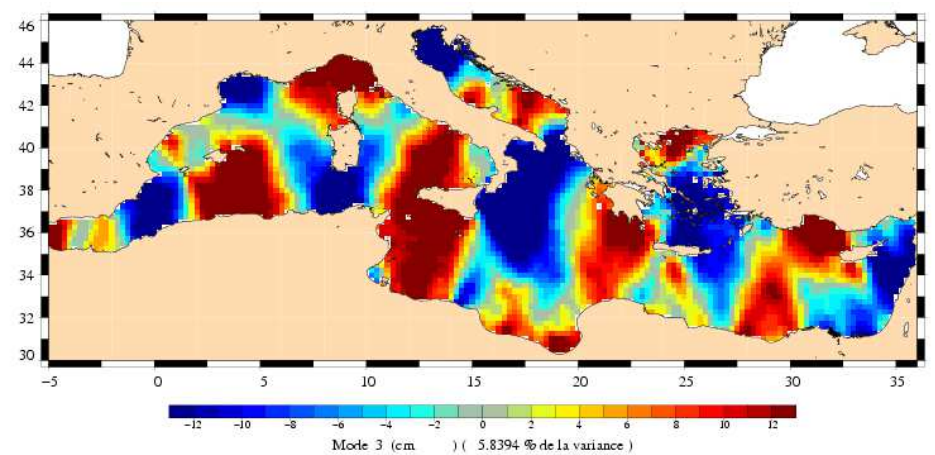

(b)

Fig. 6. EOF decomposition of the OSSE 250 signal (MOG2D signal sampled by altimetric measurement and mapped using the $250 \mathrm{~km}$ parameterisation for empirical correction of intertrack bias. Spatial component for (a) second mode, (b) third mode.
OSD

4, 571-622, 2007

Altimetric data in the Mediterranean Sea

M.-I. Pujol et al.

Title Page

\section{Abstract}

Introduction

Conclusions

References

Tables

Figures

14

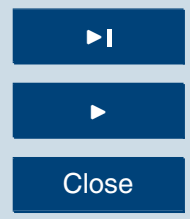

Full Screen / Esc

Printer-friendly Version

Interactive Discussion 


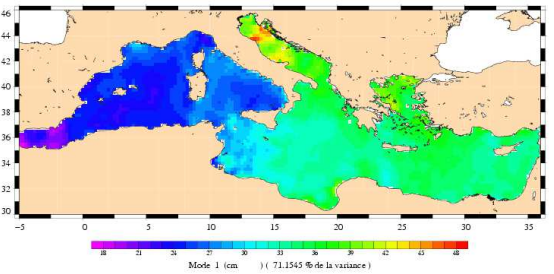

(a)

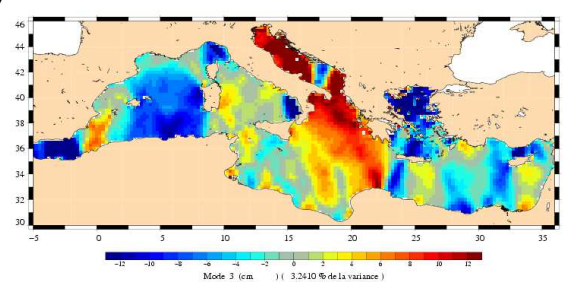

(c)

Fig. 7. EOF decomposition of the OSSE_600 signal (MOG2D signal sampled by altimetric measurement and mapped using the $600 \mathrm{~km}$ parameterisation for empirical correction of intertrack bias. Spatial component for (a) first mode, (b) second mode, (c) third mode, (d) fourth mode.

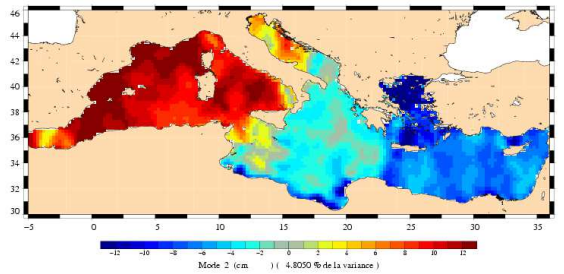

(b)

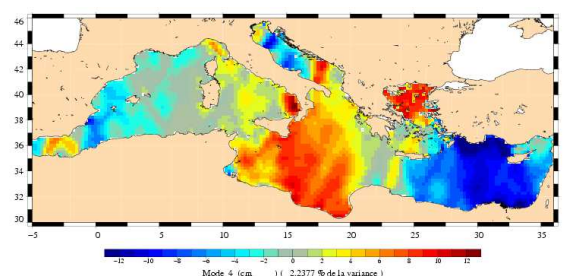

(d)

Altimetric data in the Mediterranean Sea

M.-I. Pujol et al.

Title Page

Abstract

Introduction

Conclusions

References

Tables

Figures

14

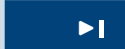

4

Back

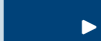

Close

Full Screen / Esc

Printer-friendly Version

Interactive Discussion 


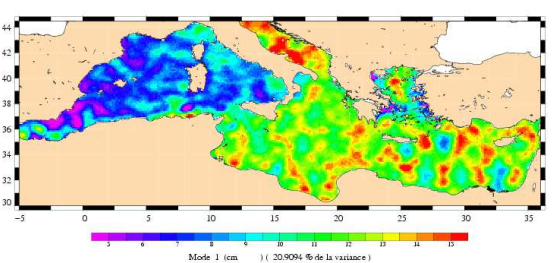

(a)

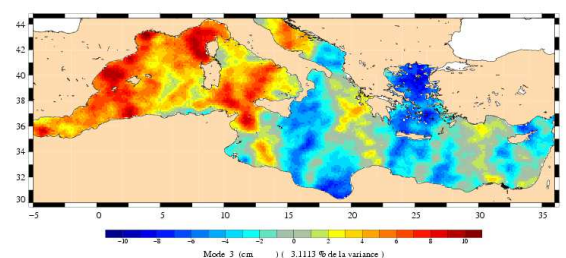

(c)

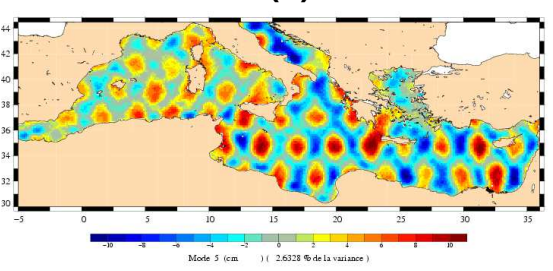

(e)

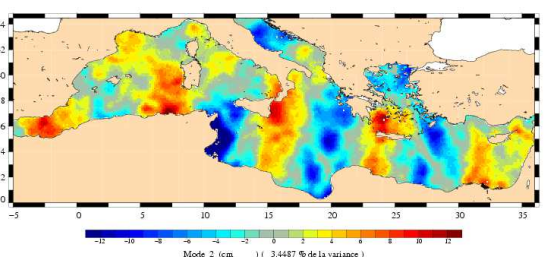

(b)

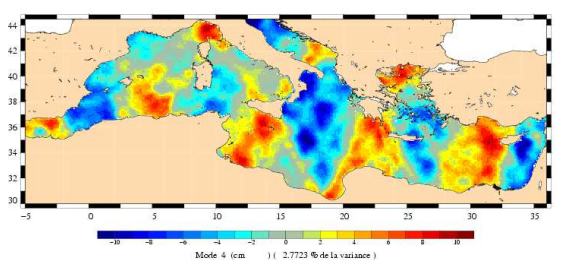

(d)
OSD

4, 571-622, 2007

Altimetric data in the Mediterranean Sea

M.-I. Pujol et al.

Title Page

Abstract

Introduction

Conclusions

References

Tables

Figures

14

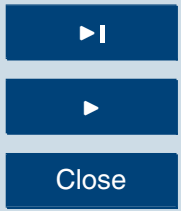

Back

Full Screen / Esc

Printer-friendly Version

Interactive Discussion bias). Spatial component for (a) first mode, (b) second mode, (c) third mode, (d) fourth mode, (e) fifth mode. 


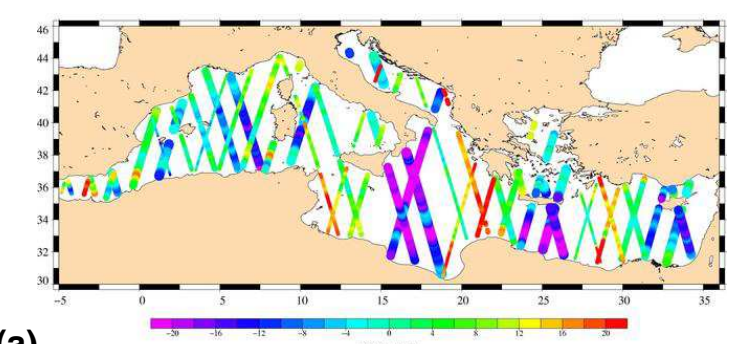

(a)

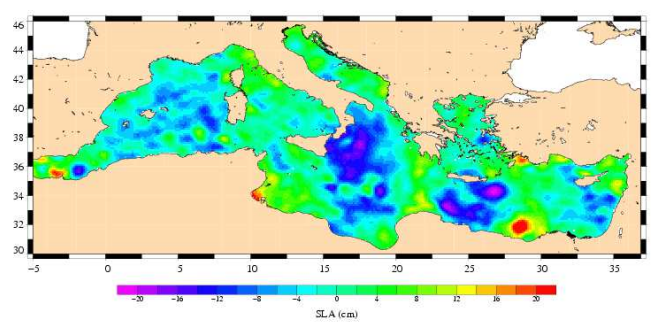

(b)

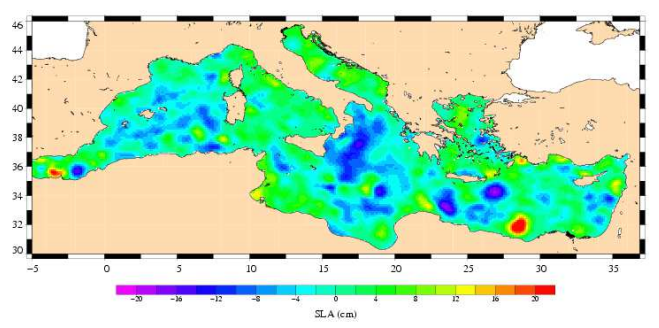

(c)

Fig. 9. (a) Along-track EN SLA data collected between 18 February and 3 March 2004. Map of SLA for 25 February 2004 deduced from these data and generated using the empirical correction of inter-track bias considering a spatial range of $250 \mathrm{~km}$ (b) and $600 \mathrm{~km}$ (c).
OSD

4, 571-622, 2007

Altimetric data in the Mediterranean Sea

M.-I. Pujol et al.

Title Page

Abstract

Introduction

Conclusions

References

Tables

Figures

14

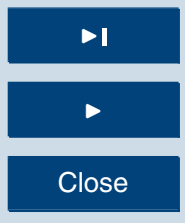

Full Screen / Esc

Printer-friendly Version

Interactive Discussion 


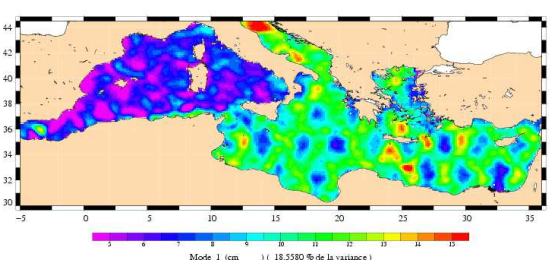

(a)

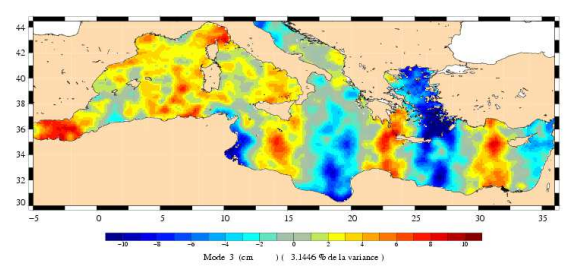

(c)

Fig. 10. EOF decomposition of the HF ( $<30$ days) component of the AOS_MOG2D signal (altimetric mapped data, corrected for inter-track bias with the MOG2D output and completed with the empirical method using the $250 \mathrm{~km}$ range). Spatial component for (a) first mode, (b) second mode, (c) third mode, (d) fourth mode. (b)
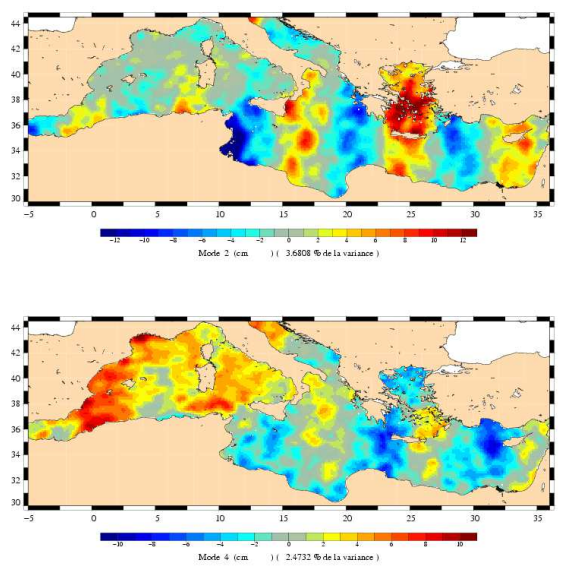

(d)

4

Back

Full Screen / Esc

Printer-friendly Version

Interactive Discussion 


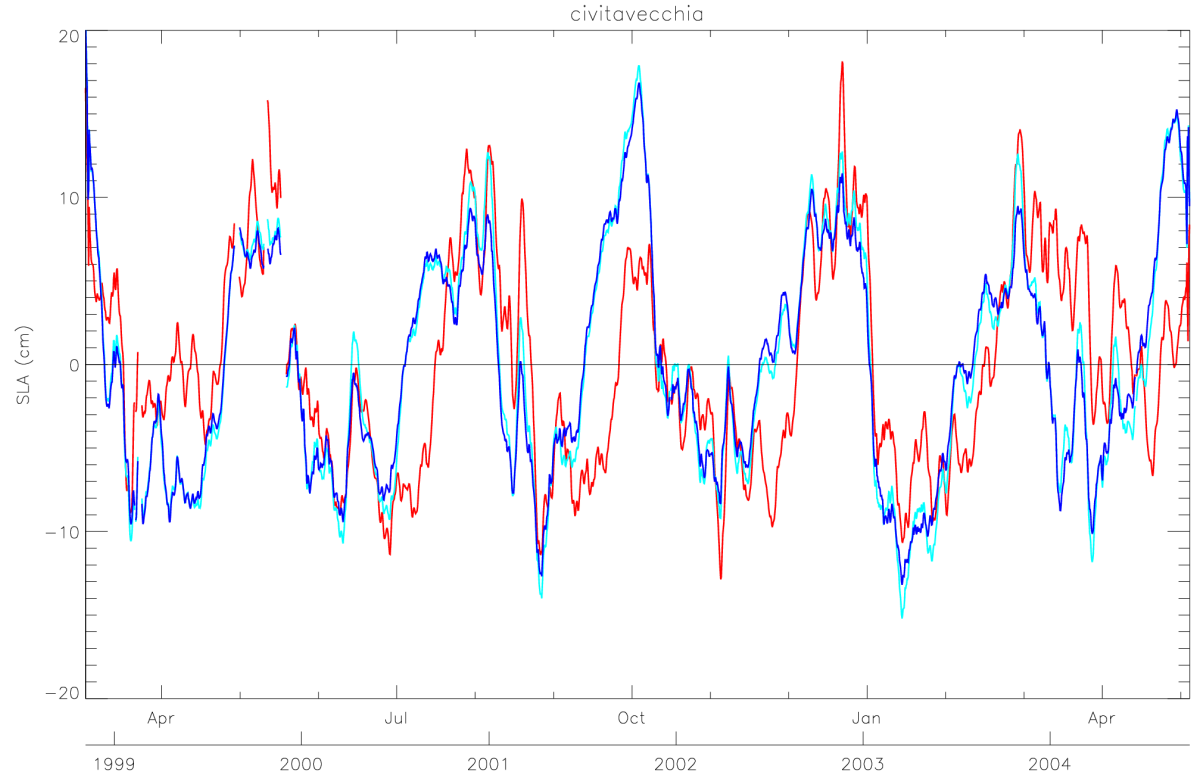

Fig. 11. Surface signal temporal variation at the Civitavecchia station. Tide gauge (red), AOS_MOG2D_LF30+MOG2D (light blue) and AOS_MOG2D_LF30+MOG2D_HF30 (dark blue) signals. For greater visibility, a 15-day running mean was applied to the data before plotting.
Altimetric data in the Mediterranean Sea

M.-I. Pujol et al.

Title Page

Abstract

Introduction

Conclusions

References

Tables

Figures

14

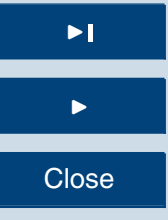

Full Screen / Esc

Printer-friendly Version

Interactive Discussion 
OSD

4, 571-622, 2007

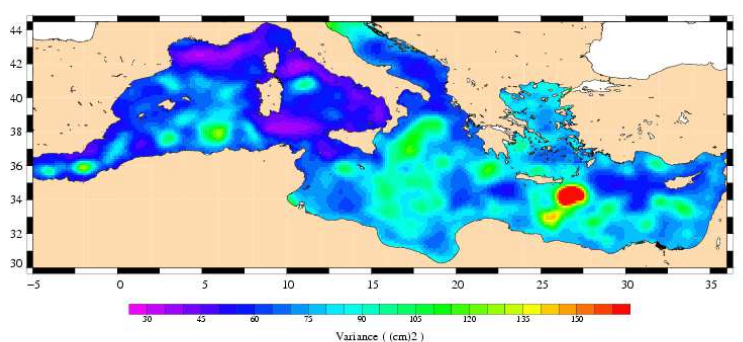

(a)

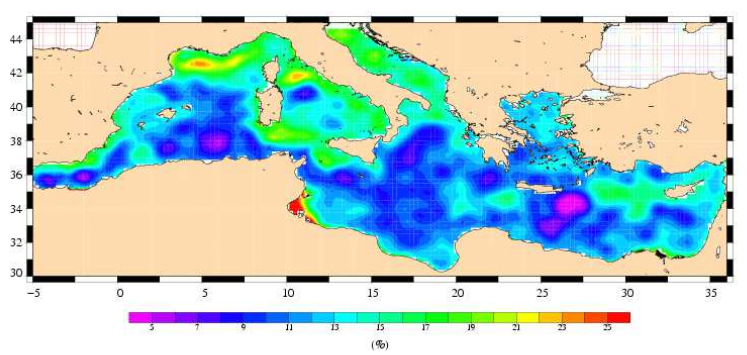

(b)

Fig. 12. (a) Mean variance of the total surface signal estimated by the AOS_MOG2D_LF30+MOG2D combination over the [1993-2003] period. (b) Contribution of the $\mathrm{HF}\left(>30^{-1}\right.$ days $\left.^{-1}\right)$ barotropic signal to the total variance.
Altimetric data in the Mediterranean Sea

M.-I. Pujol et al.

Title Page

\section{Abstract}

Introduction

Conclusions

References

Tables

Figures

14

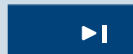

4

Back

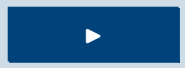

Full Screen / Esc

Printer-friendly Version

Interactive Discussion 